

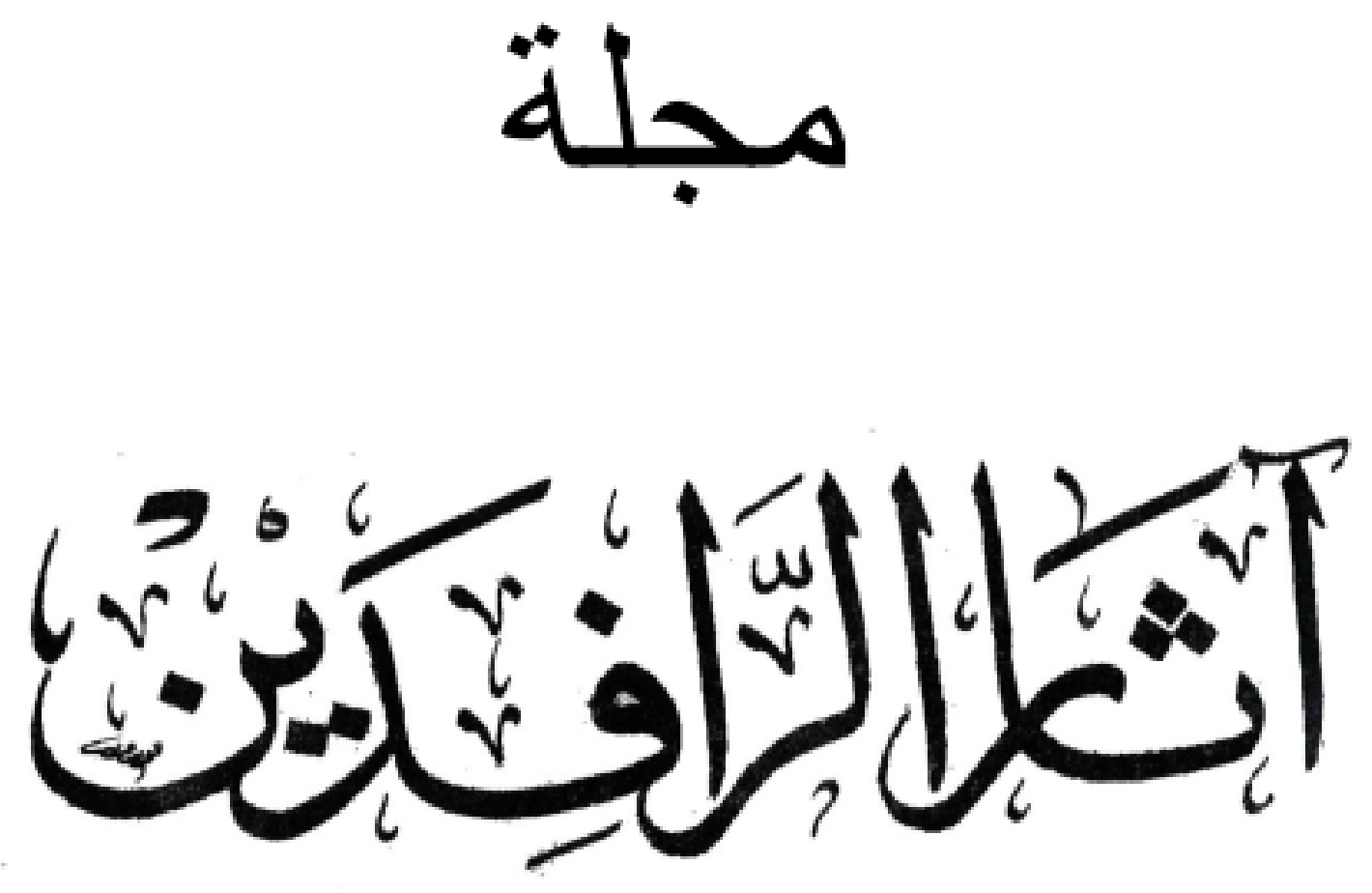

هجلة علمية همكمة تبحث في آثار العراق و الشرق الأدنى القديم تصدر عن كلية الآثار في جاهعة الموصل

E-Mail: uom.atharalrafedain@ gmail.com البريد الاكتروني

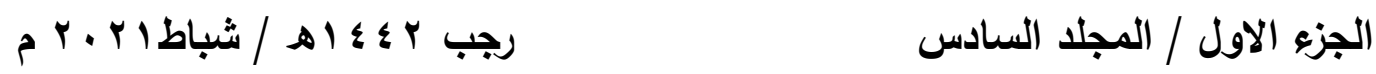

$$
\begin{aligned}
& \text { رقم الايداع في دار الكتب والوثائق بيغداد } \\
& \text { r. I السنة (IVIr) }
\end{aligned}
$$





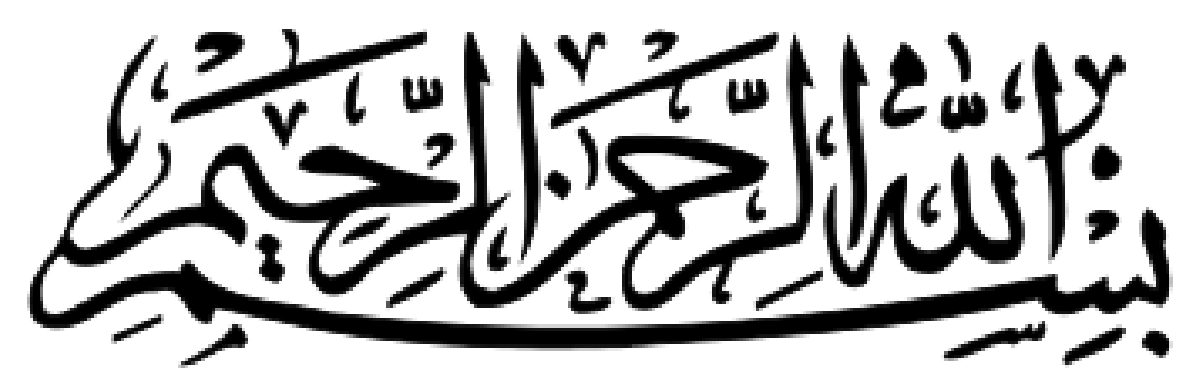





\section{هيأة التمرير}

أ. خالد سالم اسماءيل

رئيس التمرير

أ.م. هسنين حيدر عبد الواحد

الاعضاء

أ.د. اليزابيث ستون

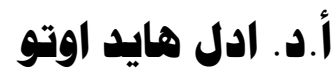

أ.د. والتز سلابيركر

أ.د. نيكولو هاركيتي

أ.د. هديب حياوي عبد الكريم

أ.د. جواد هطر الموسوي

أ.د. رفاه جاسم حمادي

أ.د. عادل هاشم علي

أ.م.د. ياسمين عبد الكريم هممد علي

أ.م.د. فيسان هوفق رشيد

أ.م.د. هاني عبد الغني عبد الله 


$$
\begin{aligned}
& \text { هقوم اللغة العربية } \\
& \text { أ.م.د. همن يميى هصمد }
\end{aligned}
$$

$$
\begin{aligned}
& \text { هقوم اللغة الانكليزية } \\
& \text { م.A. عمار احمد هميمود } \\
& \text { قسم الترجمة / كلية الآداب / جاهعة الموصل }
\end{aligned}
$$

$$
\text { د. تصهيم الغلاف البميلي }
$$




\section{قواعد النشر في هبلة آثار الرافدين}

$$
\begin{aligned}
& \text { 1- تقبل المجلة البحوث العلمية التي تقع في تخصصات: } \\
& \text { • علم الاثار بفرعيه القديم والإسلامي • } \\
& \text { • • اللغات القديمة بلهجاتها و الدراسات الدقارنة. } \\
& \text { الكتابات المسمارية و الخطوط القديمة . } \\
& \text { ه الدراسات التاريخية والحضارية . }
\end{aligned}
$$

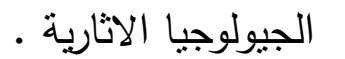

$$
\begin{aligned}
& \text { • تقنيات المسح الاثاري • }
\end{aligned}
$$

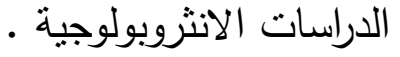

$$
\begin{aligned}
& \text { • الصيانة والتزميم الصنيم }
\end{aligned}
$$

r- تقدم البحوث الى المجلة باللغتين العببية أو الانكليزية .

r-يطبع البحث على ورق (A4)، وبنظام (2010 - word)، وبمسافات مزدوجة بين الاسطر ، وبخط Simplified Arabic للغة العربية، و Times New Roman للغة

$$
\text { الانكليزية، ويسلم على قرص ليزري (CD) ، وبنسختين ورقيتين. }
$$

ع- يطبع عنوان البحث في وسط الصفحة يليه اسم الباحث ودرجته العلمية ومكان عمله

$$
\text { كاملاً والبريد الالكتروني (e-mail). }
$$

0- يجب ان يحتوي البحث ملخصا باللغتين العربية والانكليزية على ان لا تزيد عن (· (1) كلمة.

1-يحتوي ملخص البحث بالإنكليزية على عنوان البحث واسم الباحث ودرجته العلمية ومكان عمله كاملاً والبريد الالكتروني له. V- تضمين البحث كلمات مفتاحية تتعلق بعنوان البحث ومضمونه. ^- ان لا يكون البحث قد تم نشره سابقا أو كان مقدما لنيل درجة علمية أو مستلاً من ملكية

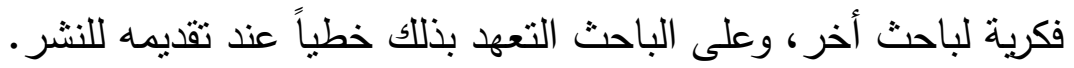
9- يلتزم الباحث باتباع الاسس العلمية السليمة في بحثه. • 1- يلزم الباحث بتعديل فقرات بحثه ليتناسب مع مقترحات الخبراء واسلوب النشر في 
11- لا تتجاوز عدد صفحات البحث عن (ro)، صفحة وفي حال تجاوز العدد المطلوب يتكفل الباحث بدفع مبلغاً اضافياً عن كل صفحة اضافية.

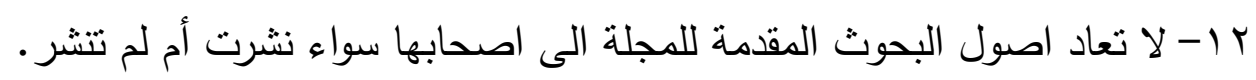
با ا-ترقم الجداول والاشكال على التوالي وبحسب ورودها في البحث، وتزود بعناوين، وتقدم بأوراق منفصلة وتقام المخططات بالحبر الاسود والصور تكون عالية الدقة. ـ ا-تكتب ارقام الهوامش بين قوسين وترد متسلسلة في نهاية البحث. 10-يشار الى اسم المصدر كاملاً في الهامش مع وضع مختصر المصدر بين قوسين في نهاية الهامش.

17 - يتحمل الباحث تصحيح ما يرد في بحثه من اخطاء لغوية وطباعية.

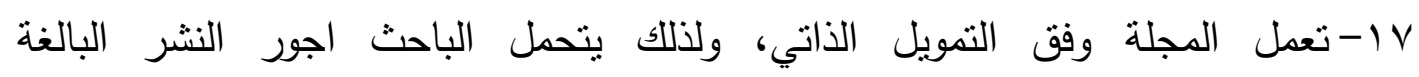

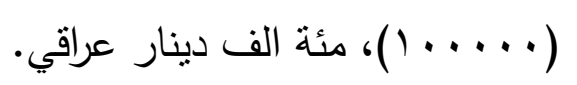

11 ا- يزود كل باحث بمستل من بحثه، أما نسخة المجلة كاملة فتطلب من سكرتارية المجلة لقاء ثمن تحدده هيأة التحرير . 9 ا - ترسل البحوث على البريد الالكتروني للمجلة: uom.atharalrafedain@gmail.com 


\section{ثبت المحتويات}

\begin{tabular}{|c|c|c|}
\hline 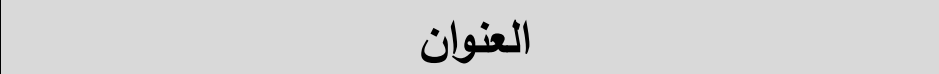 & اسم الباحث & الصفحة \\
\hline توطئة & أ. خالد سالم اسماعيل & 1 \\
\hline من ملاحم ملوك بلاد الرافدين في الألف الثاني والأول قبل & عدي عبدالوهاب النعيمي & $19-4$ \\
\hline "الفِذية" في النصوص الأكّدية & أ. د. فاروق إسماعيل & $\varepsilon \varepsilon-r)$ \\
\hline هواجس خوف الآثوريين وقلقهم من الأرواح الثريرة & أ.ديم محد صالح مصطفى صفوان سامي سعيد & $V \cdot-\varepsilon 0$ \\
\hline مدينة سيواس قبل حكم السلاجقة & أ.د. ياسر عبد الجواد المشهداني & $91-V 1$ \\
\hline التتقيات الروسية في منطقة سنجار شمال العراق & أ. أم.د. محمد كامل روكان & $11 \leq-9 r$ \\
\hline البيوت السكنية من العصر الاشوري الحديث (1) - مواقع منتخبة من منطقة مشروع سد مكحول r آج) & أ.م.د. باسمين عبد الكريم محمد علي السامرائي & $1 r V-110$ \\
\hline من الجوامع التزاثية في مدينة سنجار & أ.م.د حبدر فرحان حسين الصبيحاوي نومان الثمري & $17 \leqslant-119$ \\
\hline 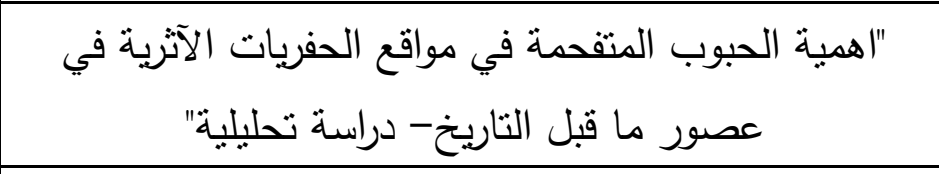 & أ.م.د. حسين يوسف حازم & $110-170$ \\
\hline 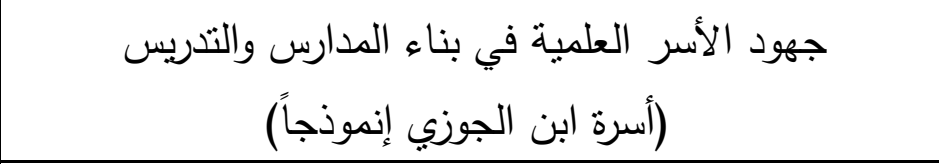 & 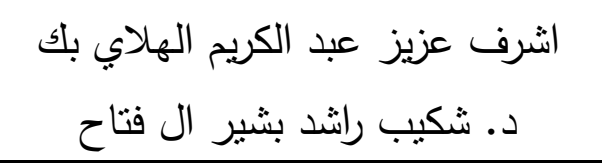 & $r \mid r-I \wedge V$ \\
\hline دوافع تحنيط الحيوانات عند المصريين القدماء & أ.م.د وسناء حسون يونس الاغا & rוT \\
\hline وصولات انجاز اللبن من مدينة بيكاسي " تل ابوعنتيك" - " & د.آرام جلال حسن الهموندي & rדו-rro \\
\hline نصوص اقتصادية غير منشورة من سلالة اور الثالثة & م.د مهند خلف جمين الثمري & rVq-rqr \\
\hline الثياطين والأرواح الثريرة في العراق القديم في ضوء النصوص المسمارية & مُشتَّى سعدون ظافر الهنداوي & $r \cdot r-r \wedge I$ \\
\hline
\end{tabular}



"الهية الحبوب المتفحمة في مواقع الحفريات الآثرية في عصور ما قبل التاريخ

دراسة تحيلية"

أ. أم.د. حسنين يوسف حازم

كلية الآثار / جامعة الموصل

hussein_1974@uomosul.edu.iq

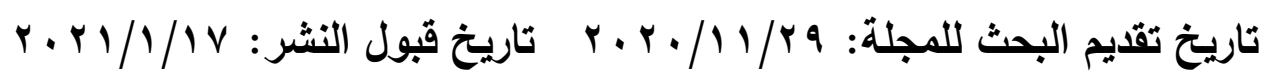

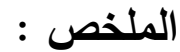

منلت الحبوب بوجه عام والمتفحمة بوجه خاص اهمية كبيرة وبالغة فضلا عن القيمة

الغذائية الكبيرة للحبوب للإنسان والحيوان واهيتها في الاستهلاك الغذائي والحياتي وما له من الهن

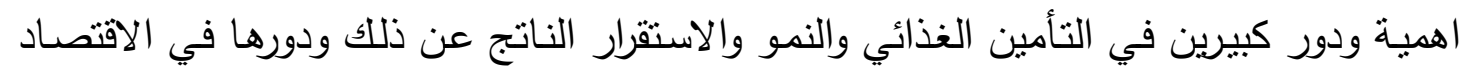

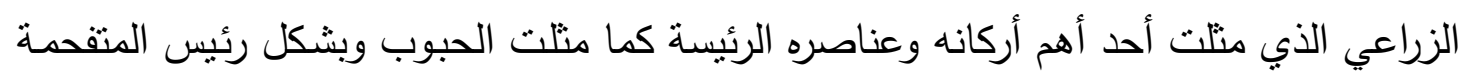

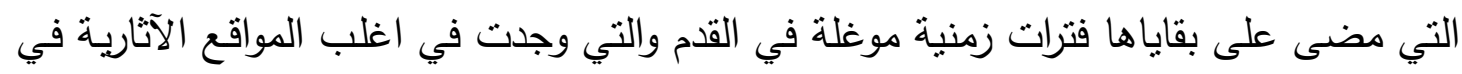

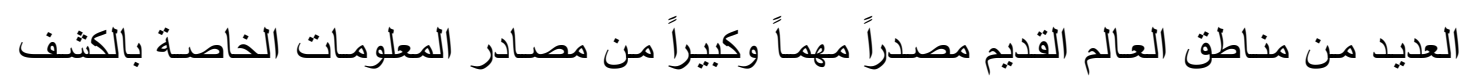

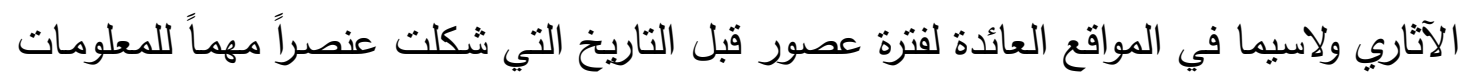

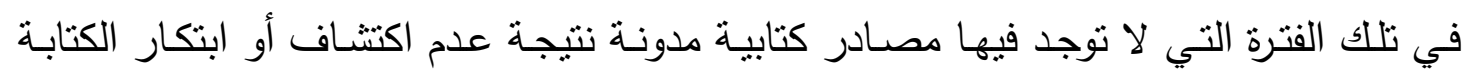

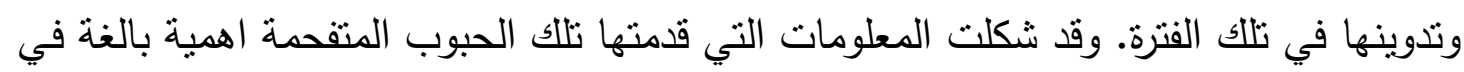
التعرف على المواقع الآثارية التي تم العثور على مخلفاتها وبقاياها والظروف البيائية والمناخية

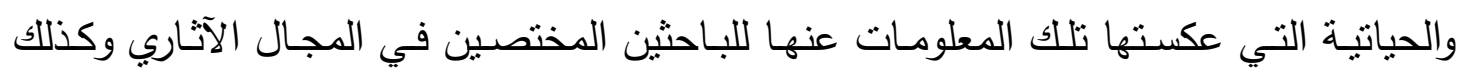

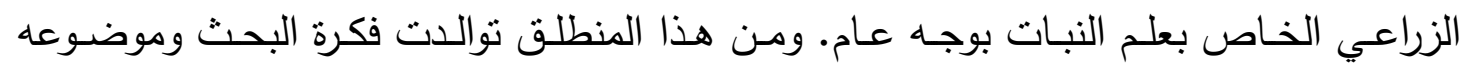

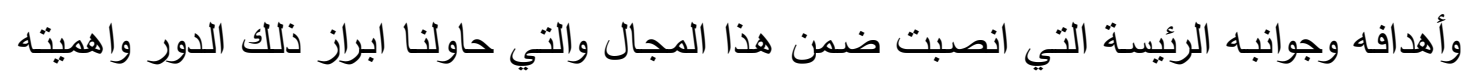

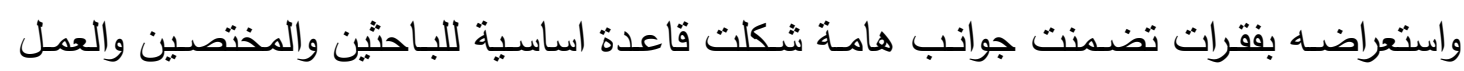

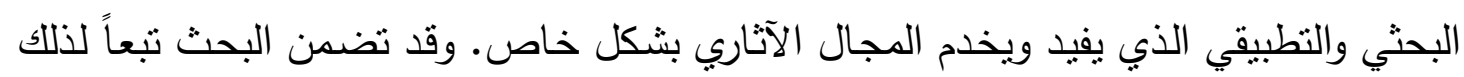

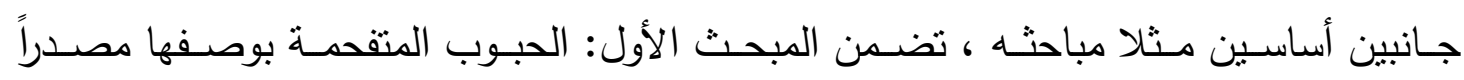

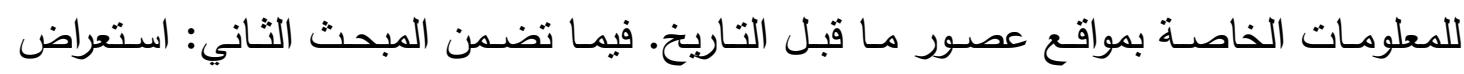

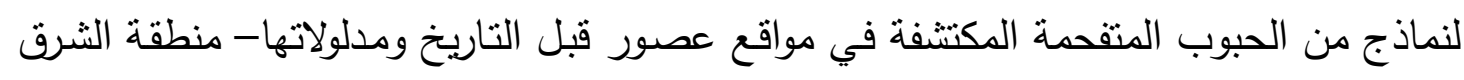

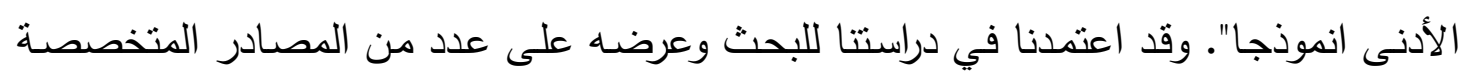

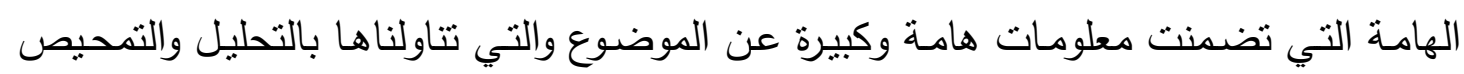




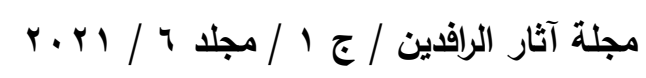

$$
\begin{aligned}
& \text { والدراسة الاستتناجية تبعا لذلك بما يتوافق مع ماهية الموضوع ومضمونه والحقيقة العلمية التي } \\
& \text { بني عليه البحث نتائجه ومضمونه. } \\
& \text { الكلمات المفتاحية: الحبوب المتفحمة، عصور قبل التاربخ، الثرق الأدنى، الحفربات الأثربة ، } \\
& \text { • الاستهالك الغذائي والحياتي }
\end{aligned}
$$

\title{
Carbonated Grains and it's Role in Archaeological Detection during Prehistory - An Analytical Study
}

\author{
Assist. Prof. Dr. Hussein .Y.Hazim \\ College Of Archaeology- University Of Mosul
}

\begin{abstract}
:
Grains in general and Carbonated in particular, were of great importance and importance in old addition to the large nutritional value of grains for human and animals, their importance in food consumption and life and their wealth of great importance and role in food insurance growth and stability the resulting result and its role in the agricultural economy which represented one of its main pillars and elements. Grains, mainly carbonated whose remains are old periods of time, which were found in most archaeological sites in many regions of the ancient world represented an important and large source of information on disburse detection, especially in the sites for the time of the passage of the right of the date which constituted an important element of information in that period when there are no written sources. The information provided by the Carbonated grains was extremely important in identifying the archaeological sites whose remnants and remnants were found and the environments, climatic and living conditions that this information reflected on them for the researchers in the archaeological field as well as the agricultural field for botany. From this standpoint, the idea of the research, it's subject and it's main aspects came. The research included: a review and clarification of the of Carbonated grains as a source of information for prehistoric sites. The second included: a review of samples of Carbonated grains discovered in prehistoric sites and their implications. We have relied in our study of research and supported on a number of specialized sources that we deal with it's valuable information in the research with analysis and scrutiny and conclusions accordingly in accordance with what is the subject and it's content and the scientific truth on which the research is based and it's results and content.
\end{abstract}

Keywords: Carbonated Grains, Prehistory, Near East, Archaeological Excavations, Food And Life Consumption. 
شكلت الحبوب أحد أهم الدحاصيل الزراعية ذات القيمة الغذائية الكبيرة للإنسان والحيوان

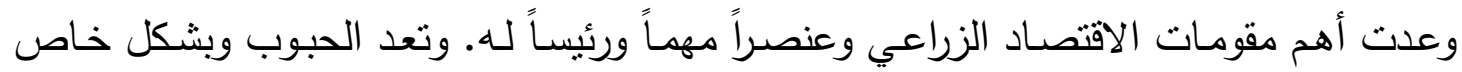

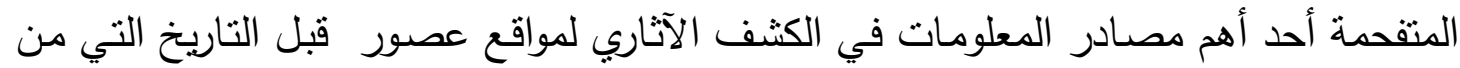

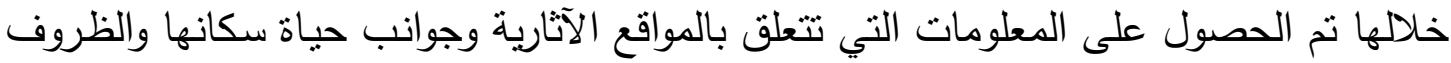
البيئية والمناخية التي يعكسها وجود بقايا ومخلفات تلك الحبوب من خلالها ظروف ونمط زراعتها والتي بدورها تسـاهم في رسم الصورة والملامسح الرئيسة والعامة للواقع البيئي والمناخي للمنطقة

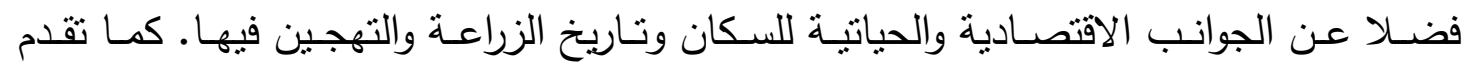

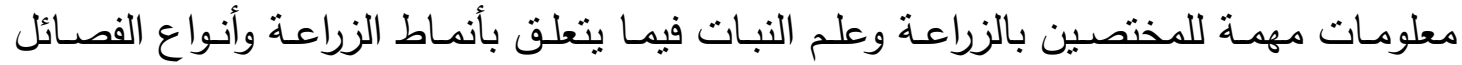
والمعلومات التي تخص البنية الجينية والمعلومات التي تخص الجانب الزراعي لها. ومن هذا المنطلق جاءت فكرة البحث وموضوعه ودراسة أهدافه و جوانبه التي انصبت

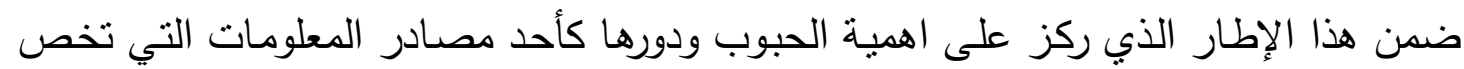

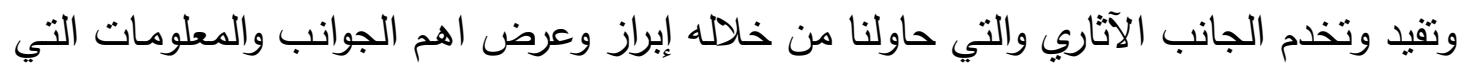

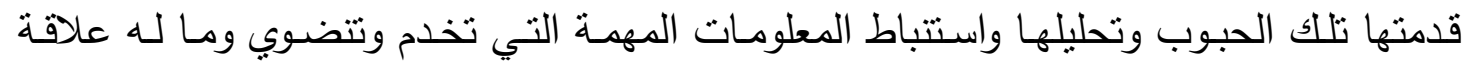
بالجانب الآثاري محور البحث. وقد جاءت دراسـة البحث وتركزت في جانبين رئيسين: ركز

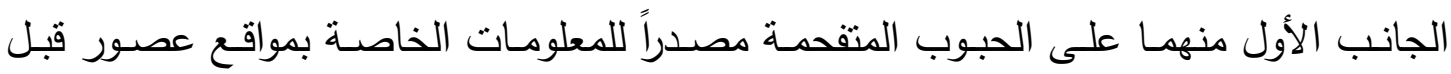

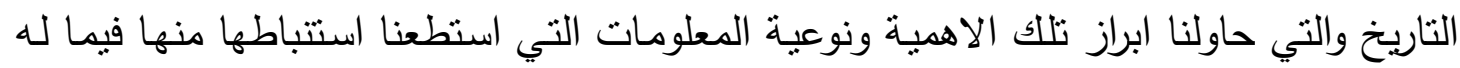
علاقة بدراسة الجوانب الآثارية وما يتعلق بها وبشكل خاص المواقع الآثارية التي ثم العثور فيها

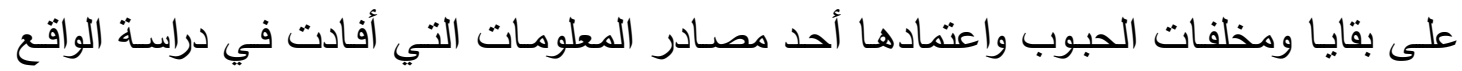
الآثاري لنلاك المواقع والمناطق العائدة لها بوجه عام. اما الجانب الثاني من البحث فيعنى بعرض

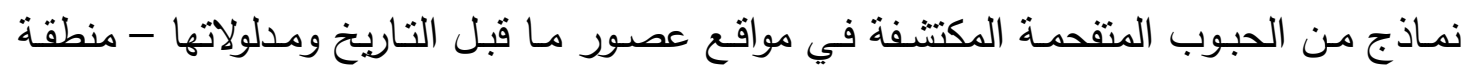
الثرق الادنى أنموذجا". وقد تم التركيز على المواقع العائدة لمنطقة الثرق الأدنى التي تم العثور

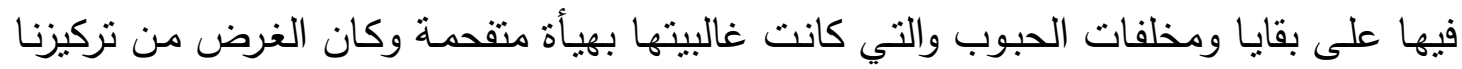
على تلك المواقع بشكل خاص كون ان منطقة الثرق الأدنى التي تعود إليها تلك المواقع تمثل

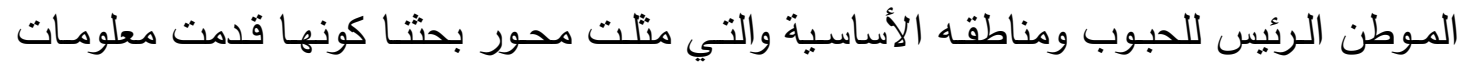

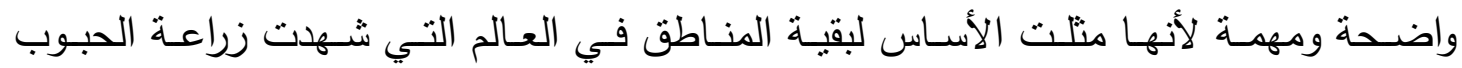

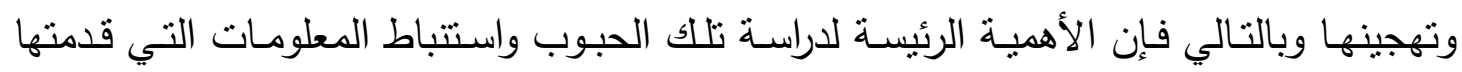
وبشكل خاص التي تتصب في مجال الكثف الآثاري تكمن في قيمتها ووضوحها وبروزها بين

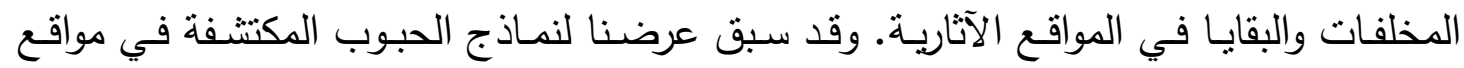


عصور قبل التاريخ استعراض لانتشار الحبوب في ومواطنها الأصلية وبشكل خاص منطقة الثرق الأدنى القديم وذلك لتتبع المناطق والمواقع الآثارية التي ظهرت فيها زراعة تلك الحبوب وامكانية استتباط المعلومات التي يمكن أن تحققها وتخدم الجانب الآثاري والحضاري التي تدعم وتفيـ في الكثـف والدراسـة الآثاريـة بوصـفها مصـدراً مسن مصـادر المعلومـات وبشـكل خـاص المعلومات المتعلقة بالجوانب البيئية والمناخية والطوبوغرافية وظروف الزراعة والتي نوهنا عنها

اعتمد البحث على عدد من المصادر المتخصصة والهامة والتي أغنت الموضوع وامدته بالمعلومات القيمة والهامة سواء العربية أم الاجنبية ومن اهمها: (وولي، هاوكس وول، أضواء على العصر الحجري الحديث، ترجمة وتعليق: سيري عبد الرزاق الجوهري، جامعة اسيوط وجامعة بيروت العربية) و (الدباغ، تقي -الجادر ، وليد، عصور ما قبل التاريخ، بغداد، بر9 () و (الجنابي، محسن علي احمد-علي، يونس عبد القادر، المدخل

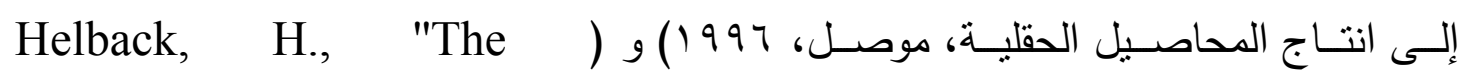
paleothnobotany of the near east and Europe", In: Prehistoric Mortensen, P., ) g (investicaions in Iraqi Kurdistan, Chicago, 1960) "Additional remarks on the chronology of early village farming .(communities in the Zagros area", In: Sumer, Vol. 20, 1964). وفي الختام نتمنى أن نكون قد وفقنا في اعداد هذا البحث وتقديم موضوعه وعرض معلوماته ونتائجه بالثكل المقبول وبما يتوافق مـع المنهجية العلمبة والبحثية الرصينة وقواعدهما ويتوافق مع الحقيقة العلمية الصحيحة ويقدم نتائجها بشكل عملي وواقعي وواضح وجلي. ومن الله

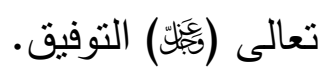


الحبوب المتفحمة مصدراً للمعلومات الخاصة بمواقع عصلية عصور قبل التاريخ: تعد الحبوب أحد أهم المحاصيل الزراعية التي شكلت قيمة غذائية لدى الانسان منذ أقدم العصور ، إذ عدت المصدر الرئيس للغذاء البشري وما تزال لاحتوائها على المواد اللازمة لنمو الانسان والحيوان (الكاربوهيدرات)('). كما انها تشكل اهمية كبيرة كأحد أبرز المحاصيل الحقلية التي تزرع بمسـاحات واسـعة والتي غالباً تتضـج في وقت واحد وتحصد في وقت واحد ايضـاً ويمكن خزنها لفترة طوبلة تحت الظروف الاعتيادية، كما تعد ضمن المحاصيل الغذائية المباشرة التي تفيد في إمداد الانسـان بحاجته مـن الغذاء الضـروري ولا تحتاج إلى علميات (direct) تحويل كبيرة. وتتدرج محاصيل الحبوب ضمن المحاصيل النجيلية التي تزرع لغرض الحصول على الحبوب للاستهلاك البشري بالدرجة الاولى كالحنطة والثعير والرز والذرة والشوفان والشيلم والدخن وكعلف للحيوانـات بالدرجة الثانية. وتكمن اهميـة تلك المحاصيل في انها تحتوي على نسبة عالية من النشأ الذي يعد المصدر الرئيس للطاقة التي يحتاجها الجسم وكذلك تحتوي على البروتينات والمواد المعدنية والفيتامينات ونسبة من المواد الدهنية وهذه المواد مجتمعة تدخل في بناء الجسم(r). كما أن الحبوب كان لها أهمية بالغة في اقتصـاد كل من العالمين القديم والجديد ففي آسـيا وافريقيـا واوروبـا شكلت الحبـوب كـالقمح والثـعير والذرة اهميـة بـارزة وزادت اهميـة محاصيل هامة اخرى كالذرة في الامريكيتنين بوصفها الدعامة الاولى للزراعة الخاصة في حضارة العصر الحجري الحديث(") مهن. وقد شكلت زراعة الحبوب الدعامـة الرئيسـة لتطور العصر الحجري الحديث بوجهه عام والزراعة بوجه خاص ولاسيما منطقة الشرق الادنى القديم، إذ أن ظهور الزراعة في هذه المنطقة أدت إلى عدها البيئة الاصلية لمعرفة أنواع مختلفة من الحبوب واهمها القمح ذو السنبلة الواحدة وهذا النوع ينمو في تربة ضعيفة، امتدت من البلقان إلى غربي ايران. بينما النوع الاخر هو من فصيلة القمح الروسي الذي يستعمل لغذاء الماشية، وقد اشتهر آنذاك في مناطق العراق وسوريا وفلسطين وشـرقي تركيا وايران (ُ)وقد مثلت زراعة تلك الحبوب في المنطقة تغيرا" أساسـا" في العصـر الحجري الحديث اذ ان زراعـة تلك الحبـوب والنتائج المتولدة منهـا أعطب فوائد جمـة ومنها المتفحمة التي خلفت بقاياها بهذا الثكل بعد مرور فترات زمنية طويلة عليها في المواقع الأثرية وعدت مصدرا "هاما" من مصادر المعلومات الخاصـة لتلك المواقع والفترات الزمنية التي مرت عليه. ويشير في الوقت ذاته الى الجهود والنشاطات التي قامت بها الجماعات البشرية في الحقبة الزمنية للعصر الحجري الحديث بشكل خاص في تهجينهم للحبوب والتعرف على أنواعها وفصـائلها على انواعها وخصائصـها يثير إلى التعمق والبحث والاستقصـاء والتحري لدى تلك الجماعات في تلك المرحلة الهامـة من حياتهم(ْ). كما يوفر الدليل الأثري الذي يثبت معرفتهم 


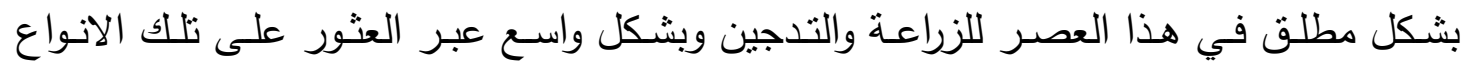

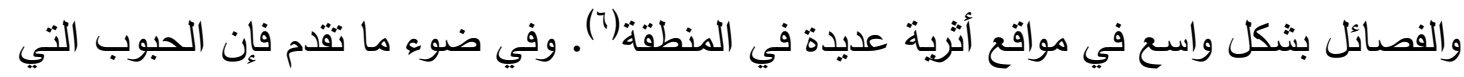

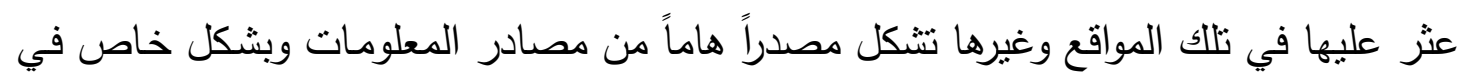

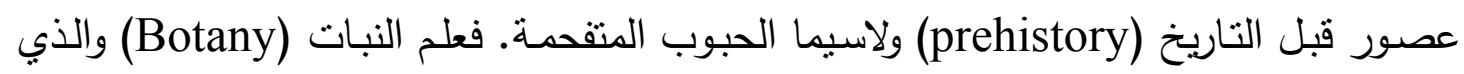

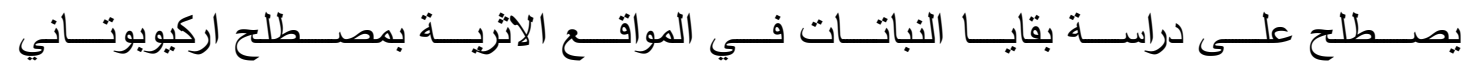

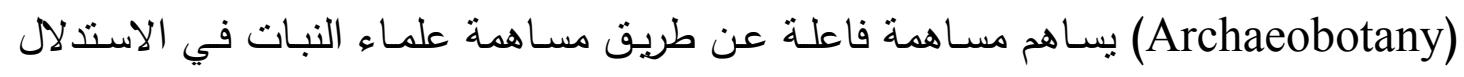

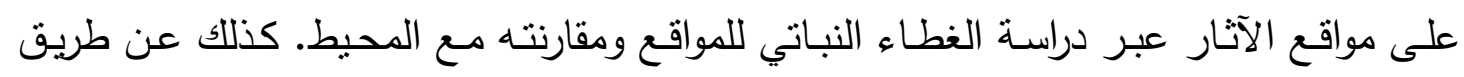

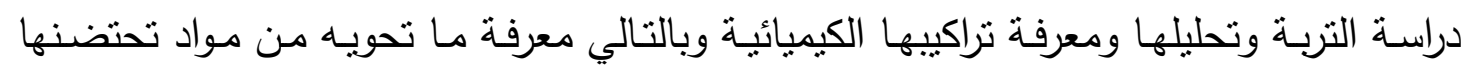

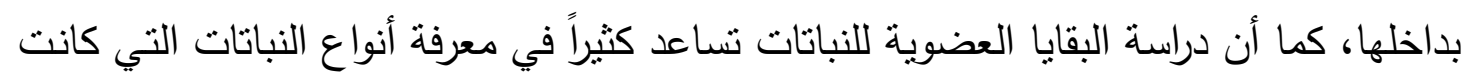

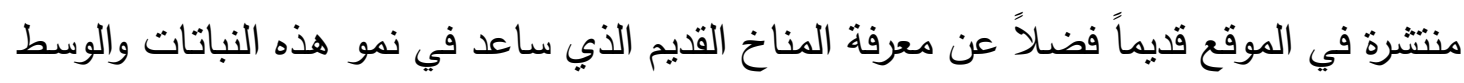

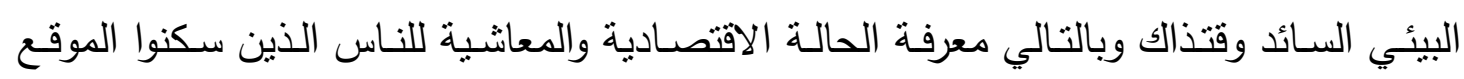

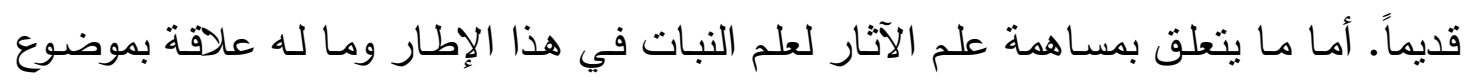

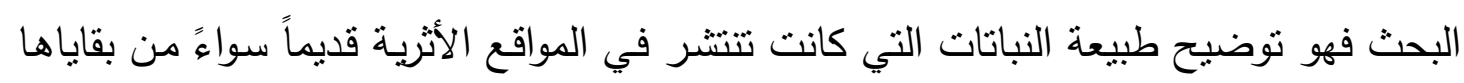

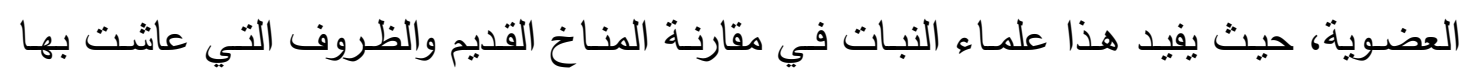

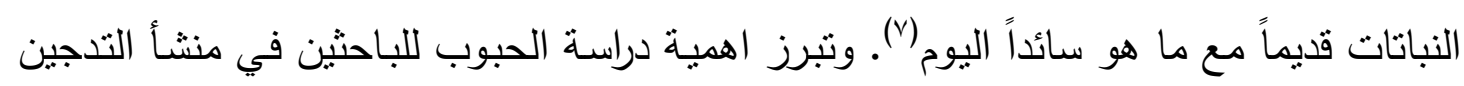

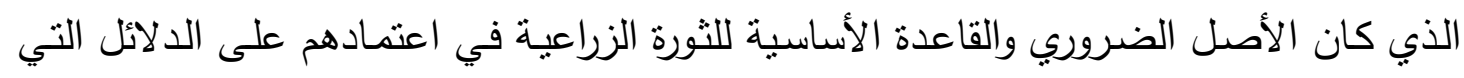

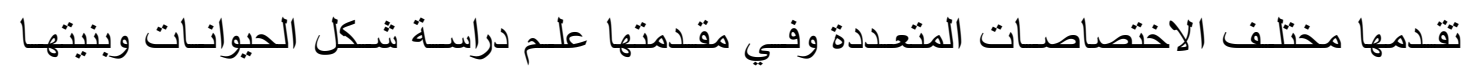

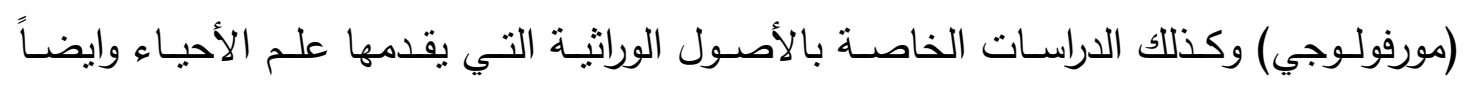

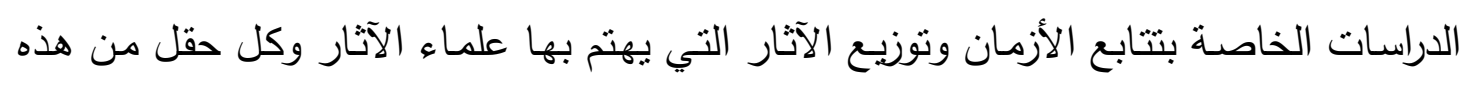

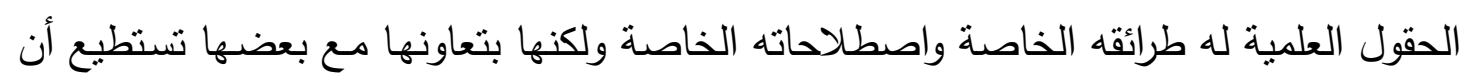

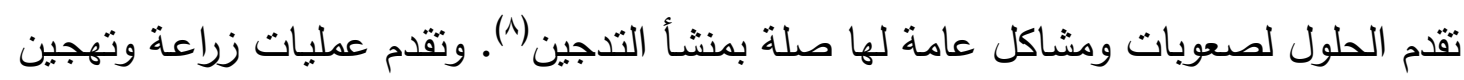

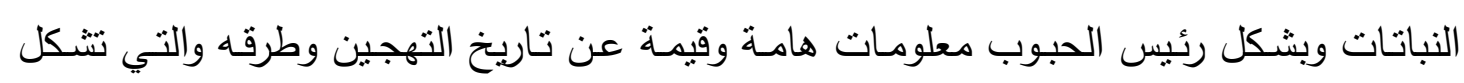

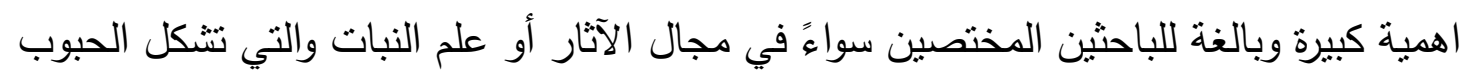

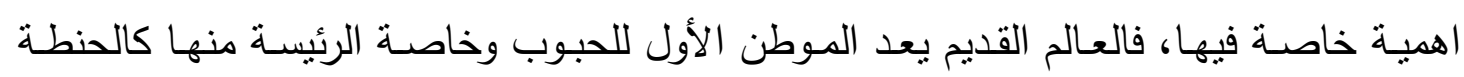

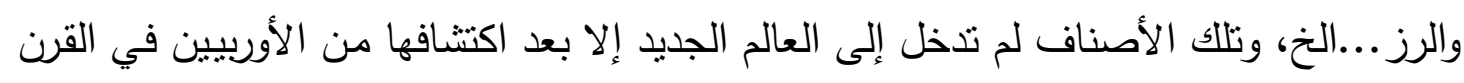

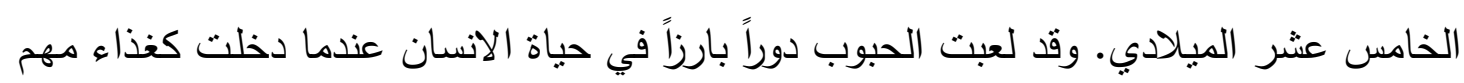

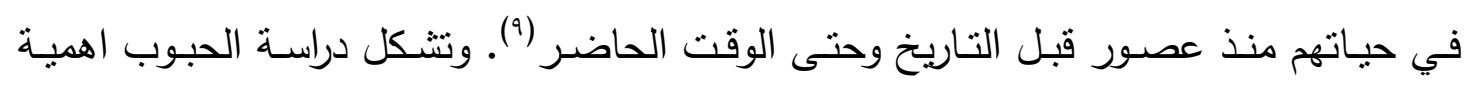

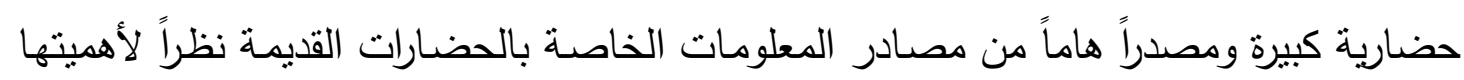

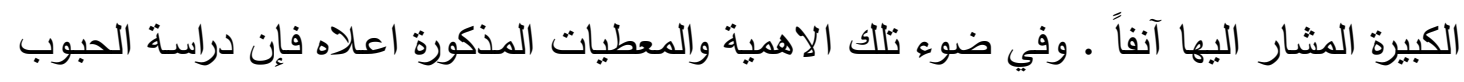
تكنسب أهية خاصة للباحثين في المجال الآثاري وبشكل خاص المختصين بفترات عصور قبل 
التاربخ التي تفتقر دراستها إلى الأدلة الكتابية المدونة لعدم ابتكار الكتابة والتدوين فيها وبالتالي تعتمد الدراسـات لتلك الفترة الطويلة زمنياً والموغلة في القدم على عدة مصـادر وبشكل خاص المخلفات والبقايا العينية في المواقع العائدة لها ومن ابرزها الحبوب المتقحمة التي مضىى عليها أو شكلت بعداً زمنياً من عمرها يمتد لآلاف السنين. وتتجسد الاهمية الكبيرة والبالغة لهذه الدراسـة في تقديمها واعطائها معلومـات هامـة وبالغـة أوضـحت الصـورة الجليـة للواقع المكاني والزماني والظـروف والجوانب التي أُتصف بها. والتي عن طريقها تم رسم الصسورة التقربييـة المجسـدة بالد لائل والعينات الملموسة التي حملتها واعطتنا استتباطات ونتائج تساعد في تحديد المعلومات وبيانها والتي تتـدرج ضـن العمـل والجانب البحثي والآثاري المختص. وتعد الطربقـة النباتيـة المتعلقـة بدراسـة النباتـات الطبيعيـة الناميـة على الموقـع أو بـالقرب منـه ودراسـة بقايـا النباتـات والحبوب الغذائية واللقاح الموجود في المواقع الأثربـة أحد أهم طرائق التاريخ النسبي الخاص بتاريخ الآثار وطبيعة المواقع الأثرية في المساعدة على معرفة احوال المناخ القديم وعلى تقدير زمنها النسبي(·) فالمناخ يعد أحد العوامل الرئيسة المؤثرة في مجمل فعاليات الانسان والحيوان والنبات وهو في الوقت نفسه ذو نأثير مباشر على حركة الاقتصاد في أية بقعة في العالم، كما انه يعد العامل الأساس الذي يتوقف عليه توزيع عالمي النبات والحيوان على سطح الأرض('"). وتمنل دراسة الحياة النباتية بوجه عام والحبوب بوجه خاص اهمية كبيرة بوصفها مصدراً للتعرف على البيئة الطبيعية وطبيعة وشكل الحياة النباتية في المناطق والمواقع الآتارية والتي تمثل ايضاً

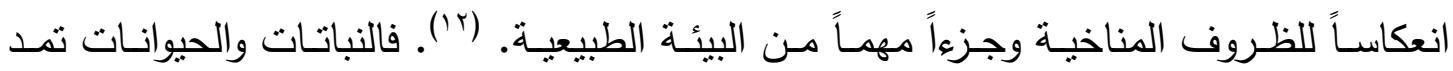

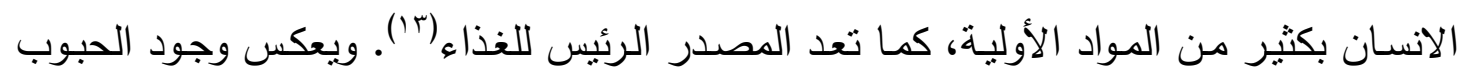
سواءً بحالتها البرية أم المدجنة الميزة والخصوصية للبيئة الطبيعيـة والطوبوغرافية للمواقع الأثربة والمنطقة بوجه عام ويعطي مؤشراً للظروف البيئة والمناخية التي كانت سائدة والتي أشرنا إلى جانب منها آنفاً وبالتالي فهي انعكاس للواقع البيئي والمناخي التي تمتعت بـه المنطقة التي تعد إلى حدٍ ما الموطن الأصلي للعديد من الفصائل البرية للنباتات والحيوانات التي دجنت في نفس المنطقة فيما بعد(ء) . ويعكس نوافر ووجود الحبوب سواءً البرية ام المدجنة في المناطق الثمالية والثـرقية والمواقع العائدة لهـا وبشـكل خـاص منطقـة الثـرق الأدنى إلى تـأثنرات منــاخ البحر المتوسط المطري على المنطقة وبشكل خاص الثتاء والربيع كما أثنارت إلى ذلك نتائج التنقيبات الأثرية ومخلفات الحبوب التي كانت متفحمة والعائدة إلى العصر الحجري الحديث وفي مقدمتها الحنطة والثعير اللذين انتشرت زراعتهما بشكل رئيس في المنطقة(10). والأمر ينطبق نفسه على مناطق البحر المتوسط الأوربية، إذ ساعدت الظروف المناخية لجنوب غربي آسيا إلى حدٍ ما في

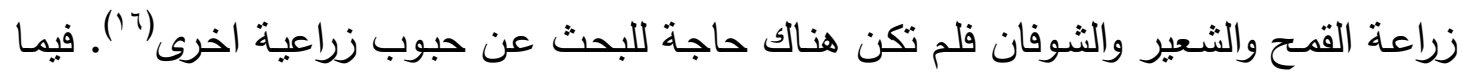


يشير وجود الحبوب في المناطق الصحراوية أو ذات التساقط المطري المحدود إلى اعتماد طرائق الري الاصطناعي أو المياه الجوفية في المواقع والقرى الزراعية الموجودة في تلك المناطق( الـ. ووفق مـا تم ذكره فـإن توافر الحبوب سواءً المتفحمـة أم البريـة أم المدجنـة في المواقـع الأثريـة والمناطق يعطي صسورة وجوانب فيما يتعلق بالبيئة الطبيعيـة والظروف المناخيـة وما لـه علاقة بظروف زراعتها، ومنها بوجهه عام معرفة نسبة التساقط المطري الذي شـهده المواقع والمنطقة بحسب الطبيعة الطوبوغرافية سواءً جبلية أم متموجة أم سهلية أم صحراوية والمصادر المائية في الموقع والمنطقة إذ أن وجود تلك الحبوب مـع المحاصيل الزراعية الاخرى يؤكد توافر ظروف زراعيـة ملائيسة لنجـاح زراعـة المحاصسيل بوجـه عـام والحبـوب بوجـه خـاص وبالتالي حصـول عمليات زراعية أو عمليات جمع والتقاط سبقت نلك العمليات الزراعية، كما يقدك صورة ودليل وجود البعد الزمني لزراعة تلك المحاصيل والتكيف لظروف البيئة والمنـاخ السـائدين وبالتالي تشكل تلك المعطيات معايير هامسة للباحثين والمختصين من الآثاربين في اعطاء صورة عن الواقع الاقتصـادي والبيئي والمنـاخي وظـروف الزراعـة التي كانت سـائدة في الموقع والمنطقة والمعايير التي يمكن الاعتماد عليها في الدراسـة والبحث الآثاري العام عما تقدم تلك المعلومات للمختصين بعلم النبات اهمية كبيرة في دراساتهم وابحاثهم النظرية والعملية واجراء التجارب وتقييم معايير الزراعة لاعم الدراسات والتجارب والممارسات العملية للعمليات الزراعية لتلك المحاصيل وتقسيم ظروف نجاحها البيئية والمناخية وما له علاقة بكميات الانتاج ومستواه نظراً لأهمية تلك ولك المحاصيل وقيمتها الغذائية وتعدد فوائدها ومجالات استخدامها المتعددة. ويؤشـر وجـود وتـوافر الحبـوب بأثـكالها واصـنافها المعروفـة مؤشـرات ومعلومـات هامـة فضـلا عن المعلومات التي امدتتا بها على الظروف البيئية والمناخيـة للمواقع الآثاريـة ومناطق زراعية فإنها تقدم صورة واضحة عن نشاطات الجماعات البشرية ووعيهم ومداركهم العقلية في التعرف والتعمق بظروف زراعة تلك المحاصيل الذي يتماشى مع الظروف البيئية والمناخية التي مر بها الانسـان من تغيير مناخي جذري انعكس على طبيعة حياته وديمومـة استمرارها والذي شكل الغذاء ركناً أساسياً فيها. فقد ارتبطت تلك النشاطات باستقرار الجماعات البشرية في سعيها الدؤوب للحصول على غذائها وتأمينه بشكل دائم مع تعرفها على مميزات وخصائص المحاصيل الزراعية والنباتات وظروف زراعتها وتهجينها عبر قيامهم بتهجين الحبوب والتعرف على أنواعها وخصائصها الذي يشير إلى البحث والاستقصاء العميق من قبل نلك الجماعات في تلك المرحلة الهامة من حياتهم من خلال قيامهم بتهجين نوعي الحنطة المعروفنين (Emmer) و (einkorn) اللذان انتشرا تهجينهما وزراعتهما على نطاق واسع في مناطق جنوب غربي آسيا ومنها العراق

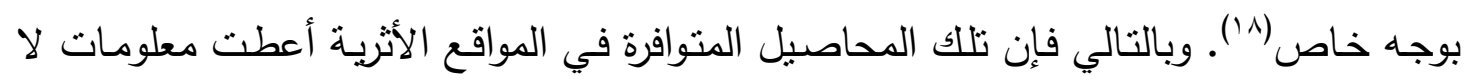
تقبل الثك في الاشارة الى مرحلة متطورة وهامـة في تطور الامكانات البشرية والذهنية والعقلية 
للجماعـات البشـرية شكلت مرتكزاً أساسـاً مـن مرتكزات العمليـات الزراعيـة ومصـدراً للمعلومـات للمتخصصين من الآثاريين فيما يتعلق بجانبهم البحثي الآثاري النظري والموقعي والمتخصصين في المجال الزراعي والقائمين عليها مما يمنل بُعداً ومرتكزاً ناريخياً وحضارياً وعلمياً، فالاختيار والانتقاء الدقيق في اختيار أصناف المحاصيل الزراعية التي تحتوي قيمة غذائية كبيرة وعالية وتوافرها بشكل مكثف وكبير وبشكل مميز وخاص في المناطق التي لا تشاعد الظروف المناخية والبيئة في نجاح زراعتها أو ملاعمتها ولاسيما في المناطق ذات التساقط المطري المحدود في المنـاطق ذات الطبيعـة الصـحراوية أو الثبه صـحراوية كما في منـاطق وقرى ام الدباغية وتل الصـوان في العراق والتي تشير نتائج التتقيبات الأثربـة التي اجريت فيهـا استتاداً إلى الأدلـة الأثرية والحبوب المتفحمة التي عثر على بقايا إلى حصول الجماعات البشرية في القرية الأولى

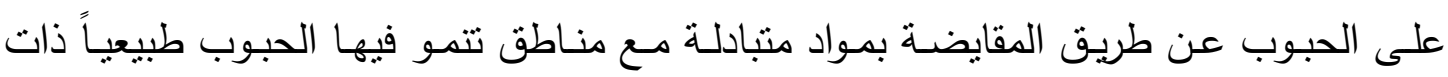
تساقط مطري عال والقربة الثانية حصول الجماعات البشرية فيها على الحبوب عن طريق الري الصناعي وفتح وشق قنوات الري(9) مما يقدم معلومات عن طريق تلك المحاصيل التي شكلت الغذاء الرئيس لتلك الجماعات عن انها الغذاء الأساس فيهما وعن نطور ونمو بشري ورصد حالة من الادرالك والتعدق الذي وصلت إلبه تلك الجماعات في معرفتهم لأنواع المحاصيل الزراعية وقيمتها الغذائية والصحية. كما يؤشر في الوقت ذاته ملاءمـة أغلب المناطق التي العثور فيها على محاصيل الحبوب بأنواعها لظروف زراعتها سواءً أكانت ذات طبيعة جبلية أو شبه جبلية أم مناطق سهوب أو مناطق ذات طبيعة رسوبية ضمن معدل سقوط مطري يتراوح ما بين ( . . ب-

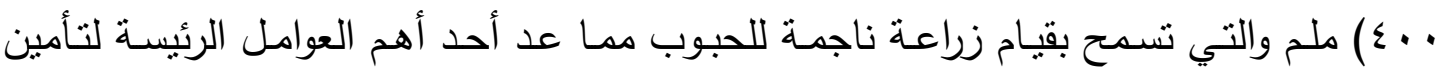
الغذاء واستمرار ديمومته في العديد من المواقع والقرى والذي مكن الجماعات البشرية فيها من الحصـول على مصـادرهم الغذائيسة بشـكل دائم ومستمر ـ كمـا تشـير مخلفـات الحبوب ولاسـيما المهجنـة منهـا في المواقـع الآثاريـة والمنـاطق العائدة لهـا وبشكل رئيس منطقة الشـرق الأدنى الموطن الرئيس والبارز لها إلى صيرورة وقيام أسس الاستيطان والاستقرار فيها وتوسع وازدياد اعداد الجماعـات البشـرية فيها استتاداً إلى بقايـا ومخلفات تلك الحبـوب والمحاصـيل الزراعيـة الاخرى المتوافرة بقاياها فيها(·) . وتدل أدلة الحبوب المكتشفة ولاسيما في منطقة الثرق الادنى القديم التي مثلت المراكز الحضارية الأولى والرئيسة التي انبثقت منها التطورات الحضارية للثورة الزراعية التي انبتقت وترسخت مع مطلع العصر الحجري الحديث إلى تكامل بنيتها الاقتصادية والتي شكلت الحياة النباتية التي تقف في مقدمتها محاصيل الحبوب والحيوانية اركانها الاساسية عن طريق تعدد وتتوع تلك المحاصيل بشكل أساس في اجزائها أو الاجزاء المحاذية لها كما في حافات الصحاري منت الصحراء السورية أو السهولة الجبلية في الاناضول وايران والتي نمت فيها 
الاسلاف البرية للحنطة والثعير التي تميزت بارتفاعها البالغ مايقارب( . . . r - . . ب) قدم فوق مستوى سطح البحر ووجود الحنطة الرئيسـة بنوعيها (Einkorn) التي امتدت من البلقان إلى سلى غرب ايران و (Emmer) الذي تم العثور على بقايـاه في منـاطق شـمال العراق، شـرق تركيا، ايران، جنوب سوريا، فلسطين والاردن ('r). وقد شكلت تلك المناطق مراكز ابتدائية لتهجين تلك المحاصيل والمحاصيل الزراعية الاخرى إلى جانب المراكز الاساسية الاخرى في العالم في شرق آسيا، Sub-Saharan، أفريقيا، امريكا الوسطى وامربكا الجنوبية والتي منلت المراكز الاساسية لتهجين تلك المحاصسيل والتي انتشرت زراعتها في العـالم القديم بين منطقة البحر المتوسط وافغانستان في فترة ما بعد الألف العاشر قبل الميلاد(r؟).

كما شكل وجود تلك الحبوب في المواقع الأثرية لتلك المراكز أُسس قيام القرى الزراعية الأولى فيها وفي المنطقة والتي شكلت زراعة تلك الحبوب فيها في العصر الحجري الحديث في للمدة ( . . . - . . . 9) ق.م مرتكزاتها الزراعيـة الأولى (rr). وقد شكل ذلك مصدراً هاماً ورئيساً من مصادر المعلومات على حضارة تلك المراكز وبنيتها الاقتصادية والحضارية من جهة والواقع الزراعي وظروف الزراعة وانواع المحاصيل الزراعية التي كانت سائدة فيها والتي مثلت قاعدة رئيسة في تتبع زراعة تلك الحبوب ومناطق انتشارها والبيانات العائدة لها بالنسبة للمختصين بعلم النبات والزراعة.

نماذج من الحبوب المتفحمة المكتثفة في مواقع عصور ما قبل التاريخ ومدلولادتها - منطقة

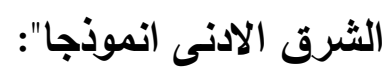

مثلت الحبوب أحد أهم المحاصبل الزراعيـة التي شكلت مـادة غذائيسة أساسية للإنسـان والحيوان منذ أقدم العصور التي مرت على الحياة البشرية وشكلت ركنا" هاماً من أركان وجوانب

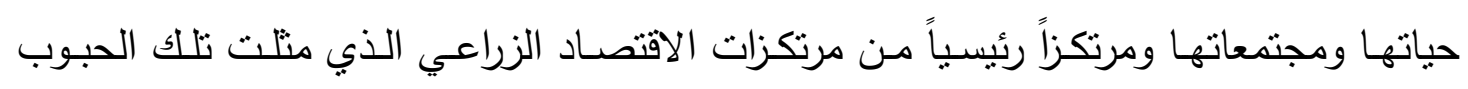
عنصرها الأول والهام بوجه خاص. وبالنظر لأهمية ذلك المحصول وقيمته الغذائية والاقتصسادية الخاصـة وسعة منـاطق انتشـاره وسـة اسـتخداماته و ســـاول في هذا الجانب مـن البحث أن نسـتعرض أهـ منـاطق انتشـار الحبـوب في منطقة الثـرق الأدنى بوجـه خـاص ولاسـيما أبـرز

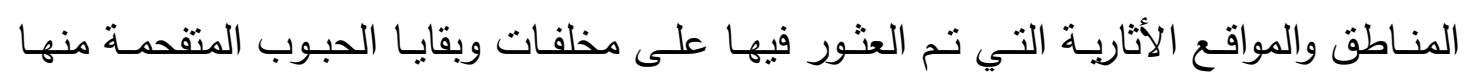
وماقدمته من معلومات ومدلولات خاصة تتعلق بها. 
مثّل العراق أحد أهم مناطق الثُرق الأدنى التي شهدت انتتـاراً واسعاً وكثيفاً للحبوب

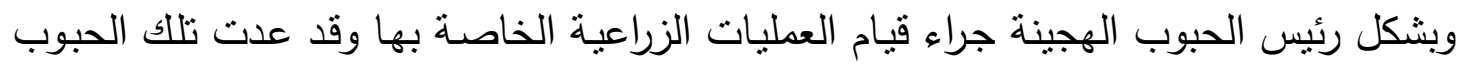
احد اهم مصادر المعلومات في الكثف الآثاري للمواقع التي عثرت فيها على بقاياها ومخلفاتها بوجه خاص والعراق بوجه عام وقد اخترنا ابرز المواقع التي تعود لبيئات مختلفة تم العثور فيها

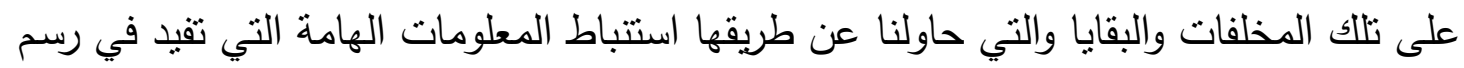

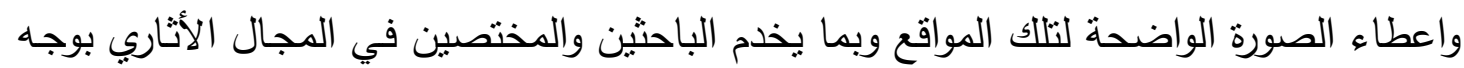

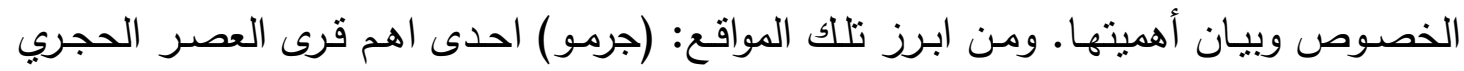

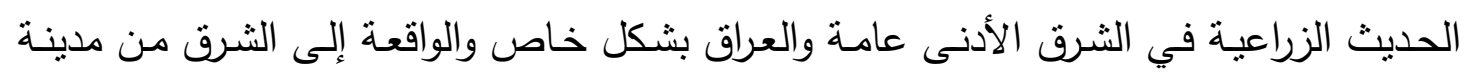

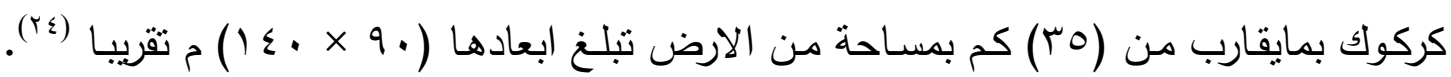

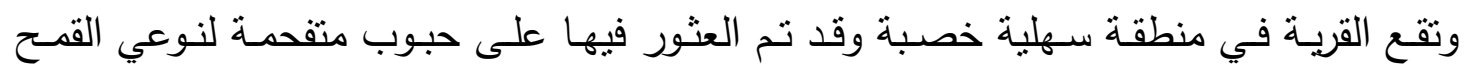
المعروف (Emmer) و (Einkorn) ونوع الثعير المهن المعروف (H.distichum)(ب0). كما فيا

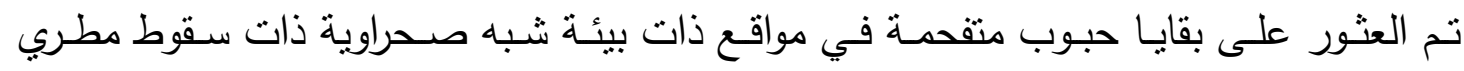
متذبذب تم رصد بقايا تلكك الحبوب فيها على الرغم من تباين الظروف البيئية والمناخية المتعلقة بزراعتها ونحوهما في تلك القرى إلا أنها قدمت معلومات هامة تمثلت بالرغبة الحقيقية للجماعات

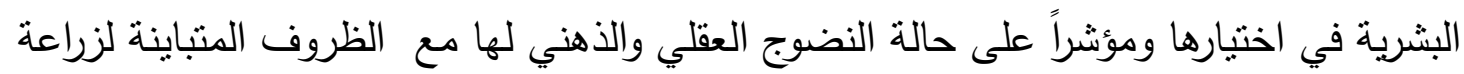

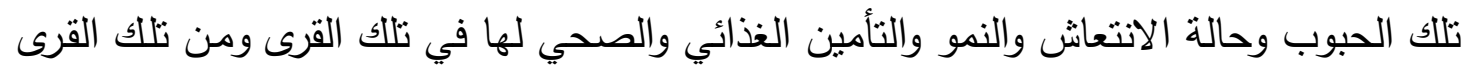

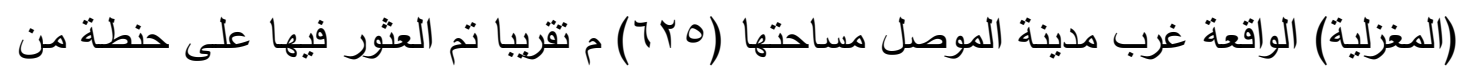

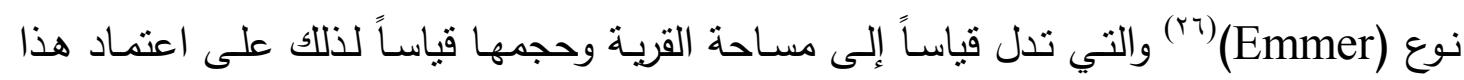

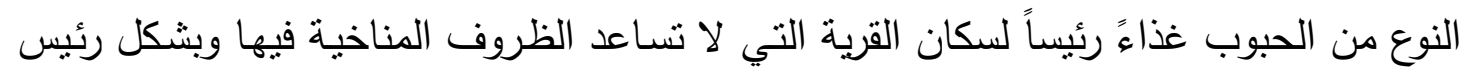

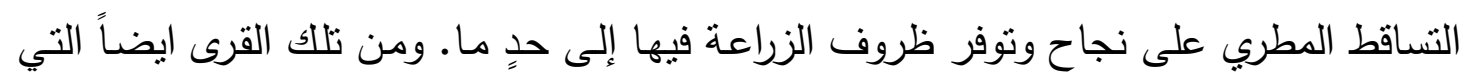

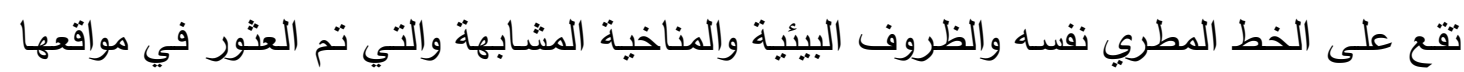

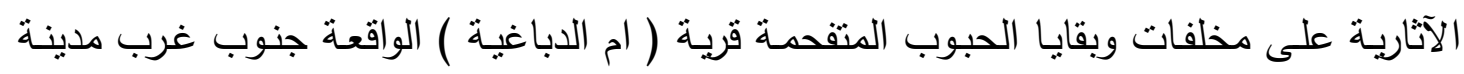

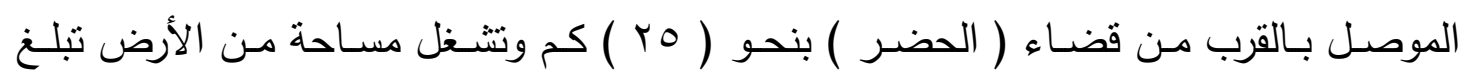

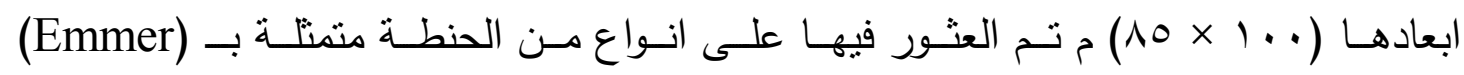

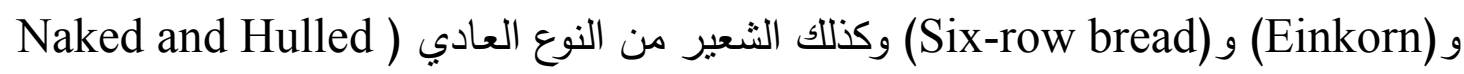
(Barly

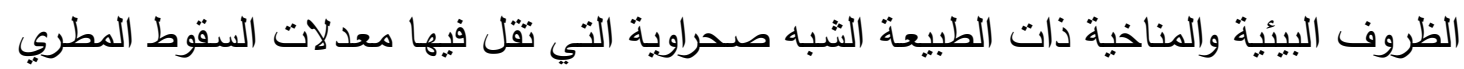
يدل على قيام سكان القرية إلى بجلب تلك الحبوب من مناطق ذات سقوط مطري عال مقابل 
مقايضتها بمواد متوفرة فيها كالجلود ومنها جلود حيوان ( الأونيكر ) كما أثنرنا آنفاً(^^). وبالتالي فقد أمدتتا الحبوب المكتشفة في هذه القرية على معلومنين أساسيتين هما تحديد العنصر الغذائي لسكان القربة المتمنلة بالحبوب وقيام عمليات المقايضة التي تمنل الأسس الأولى لعمليات التبادل

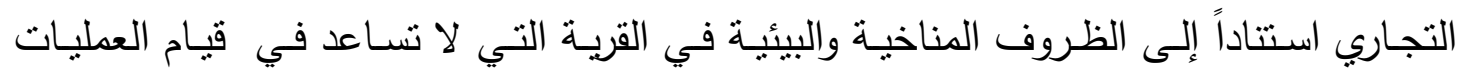
الزراعية بها دائماً. وتتطبق الحال ذاتها على قريـة ( الصـوان ) الواقعـة جنوب مدينـة سـامراء (1 (1) كم تقريبا (19). والتي تم العثور فيها على مخلفات وبقايا حبوب القهـ والتي دلت أدلة التنقيبات والتحريات الأثريـة إلى اعتمـاد زراعـة تلك الحبوب ومحاصيل اخرى على الري لعدم توافر المستوى المطري الكافي لنمو تلك الحبوب والمحاصيل(·r). وبالتالي فأن تلك الحبوب بوجه خاص اعطنتا معلومات عن وجود عمليات الارواء الاصطناعي (الري) مما شكل اهمية كبيرة للباحثين المختصين في المجالين الآثاري والزراعي.

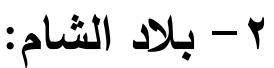

شكلت المواقع الأثريـة التي تم العثور فيها على مخلفات وبقايا الحبوب ومنها المتفحمة في بلاد الثام اهمية كبيرة وبالغة امدتتا بمعلومات قيمة وكبيرة عن تلك المواقع والمناطق العائدة، إذ شهدت قيام عمليات تهجين للعديد من المحاصيل الزراعية وبشكل أساس الحبوب إلى جانب المحاصبل الزراعية الأخرى(ب). وقد شهدت العديد من مواقع بلاد الثـام القديمة زراعة وتهجين الحبوب وبشكل رئيس في (الدور النطوفي) إذ تعلم السكان الزراعة، إذ تم العثور على حبوب القمح والثعير بهيأة برية وبشكل خاص في شمالي سوريا(r؟r). وتعد هذه الفترة مهمة كونها الفترة التي نشأت فيها بذور الثورة النيوليتية (العصر الحجري الحديث) التي تبلورت لاحقاً في الفترة النيوليتية. وتسمية الدور النطوفي أو الفترة النطوفية نسبة إلى وادي النطوف (مغارة شقبة) في فلسطين وهو المكان الأول والمبكر الذي عرف الباحثين على مميزات حضـارية لفترة لم تكن معروفة من قبل(rrr). وسنحاول في هذا البحث أن نستعرض أبرز المواقع الآثارية في بلاد الثـام التي تم العثور فيها على بقايا ومخلفات الحبوب ومنها الحبوب المتفحمة والمعلومات التي قدمتها في عمليات البحث والكثف الآثاري ومن تلك المواقع (سهل العمق، ثل كوردة، تل الذهب) وفي سهل البقاع في (اللبوة) و (كرد التليلي) وحضارات تلك المواقع كانت تعتمد على زراعة حبوب

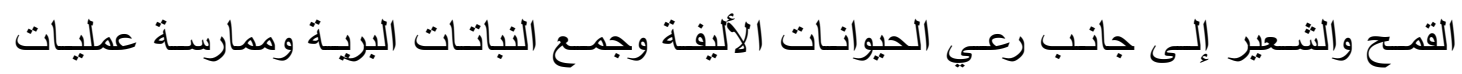
الصيد(عَ) وتعكس الحبوب المكتشفة في نلك المواقع وبشكل خاص في سهل البقاع الذي يعد أحد الأقسام الجغرافية من بـلاد الثـام وهو سهل ضيق يبدأ شمالاً من المنعطف الثمالي لنهر العاصي حيث يكون سهلاً عربضاً نوعاً ما هو سهل العمق(ro) عن الظروف البيئية والمناخية في مون 
المنطقة وعن توافر المصادر المائية فيها فضلا عن قيام أنشطة اقتصادية زراعية وحياتية فيها اعتماد تلك الحبوب المادة الغذائية الرئيسة فيها.

ومن المواقع الأثريـة التي تم العثور فيها على مخلفات الحبوب وبشكل اسـاس البربـة (القهـح والثـعير) ضـمن الخط المتذبذب أو المحدود موقع (ابو هربرة) النطوفي (على الفرات الأوسط) عثر فيه على مخلفات الثعير البري بشكل خاص، إذ يقع هذا الموقع في المناطق الداخلية ذات الهطول المطري المحدود. وقد أفادتتا المعلومات المـأخوذة من تلك الحبوب في الموقع والمنطقة بوجـه عـام إلى اعتمـاد السكان في غذائهم مـن تلك الحبوب التي لا تحظى عمليات زراعتها بظروف ملائمة إلى اعتمادهم على الحبوب منها، وربما إلى عدم قيامهم بزراعة الحبوب حسب ذلك العامل وسكنهم في الموقع بشكل غير ثابت، إذ يشير بعض الباحثين إلى أن الموقع قد سكن بشكل مؤقت لغرض الصبد وقد أستقر السكان في بيوتهم الأساسية وإن لم يكن بشكل دائم ولكن بشكل شبه مستقر (َr). ومن المواقع الآثاريـة الهامـة التي تم العثور فيها على مخلفات الحبوب موقع (مريبط) الواقع في شـرق سوريا على الضفة الثـرقية من نهر الفرات على بعد (·^) كم جنوب شرق

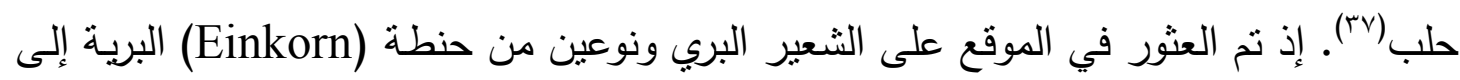
جانب قيام السكان بالتقاط العدس والفستق وانواع نباتية اخرى. ونتير المعلومات المأخوذة من الموقع ذاته وبحسب الطبيعيـة البيئية والمناخيـة فيها ومـا تم استتباطه من المعلومات الخاصـة بالحبوب فيه إلى محاولات بدائية لزراعة تلك الحبوب والزراعة بوجه عام واعتماد السكان على عمليات الجمع والالتقاط بدليل العثور على آلات حجريـة كالمقاشط والمثاقب وسـهام فضـلا عن اعتمادهم على صيد الحيوانات كالحمير الوحشية والغزلان وغيرها. عما أن التاربخ المبكر للموقع التع

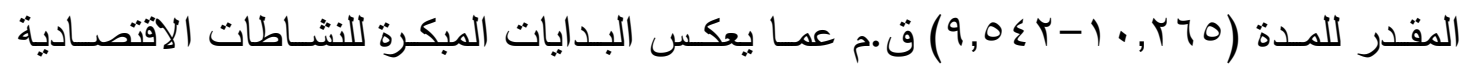
والحياتية للسكان وبشكل خاص زراعة الحبوب التي شكلت اهمية كبيرة للسكان وحرصهم على توفيرها بشتى السبل سيما ان حجم الموقع كبير واحتوائه على ما يقارب من ( . . ب) بيت دائرية

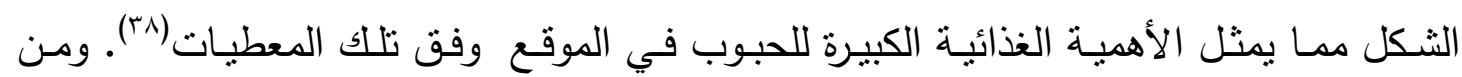
المواقع الآثاريـة التي تم العثور فيها على مخلفات وبقايـا الحبوب موقع ( اريحا ) الواقع إلى الثمال من منطقة البحر الميث(ج") ويعود الموقع إلى العصر الحجري الحديث لفترة مـا قبل

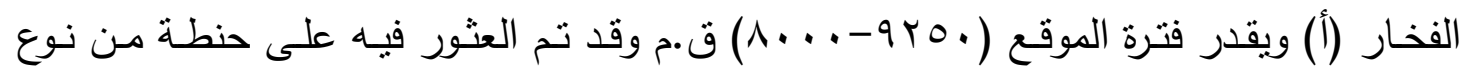
بكميـات وافـرة والثـعير المغلـف ذي السـنبلة ذات الحبتـين (•؛ (Einkorn) المكتشفة في الموقع معلومات عنه وعن المنطقة ومن ضمنها ازدياد حجم الموقع وعدد سكانه إذ وجدت بقايا قرية كبيرة تمثلت بالموقع ذاته عرف سكانه الزراعة الأولى للقمح والشعير وسكنوا في 
بيوت منتظمة مستخيرة أو بيضوية مبنية من الحجر ومن اللبن ومطلية جدرانها بالطين((ع). وهذا يعكس تطور اهل القربة ومستوى وقابلياتهم لزراعة الحبوب والمستوى العام لتطور الزراعة فيها وطبيعة النشاطات الاقتصـادية والحياتيـة المبكرة للموقع وتاريخه كمـا يعكس مستوى الاستهلاك البشري فيها وحجم السكان الذي منلت الحبوب غذائهم الأسـاس بالاستتاد إلى طبيعة الحبوب المكتشفة والمعلومات الواردة منه ولاسيما ما يتعلق بحجم ونوعية البيوت فيه.

(

شكلت المواقع الآثارية في مصر والتي تم العثور فيها على مخلفات الحبوب احد اهم تلك المواقع التي شكلت الحبوب فيها أحد أهم مصـادر المعلومات لتلك المواقع والمنطقة بوجه عام على الرغم من ان ظروف زراعة تلك الحبوب تختلف عن نظيراتها في المناطق المعاصرة لها في الثرق الأدنى كالعراق وبلاد الثام وايران والاناضول بسبب ظروفها البيئية والمناخية ذات الطبيعة الصحراوية التي تميزت بتذبذب نسبة السقوط المطري والذي حتم اعتماد الزراعة فيها على المياه وبشكل رئيس نهر النيل الذي يميز مصر في جغرافيتها وتاريخها الذي عد مصدر الحياة والخصب(r)؛. وقد بدأت الزراعة في مصر بوجه عام والحبوب وجـه خاص مـع بدايات العصـر الحجري الحديث، إذ كانـت احوال المنـاخ مواتيـة لحدوث الثورة الزراعيـة أو مـا يسـىى بـالانقلاب الاقتصـادي الذي شـهد العصر في حياة السكان. وكانت قرى هذا العصر تقع في مصـر العليـا ومصـر السـفلى وكـان هنـالك كثيـر مـن الأمـور المشـتركة بينهـا في الزراعـة

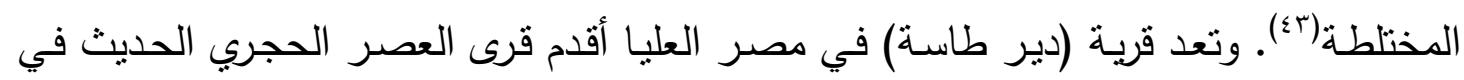
مصر وتقع على ضفة نهر النيل الثرقية إلى الثمال من تل العمارنـة. وقد تم العثور في موقع القربة على مخلفات الحبوب والتي أثتبت معرفتهم بالزراعة ووجدت تلك الحبوب في بيوت سكان

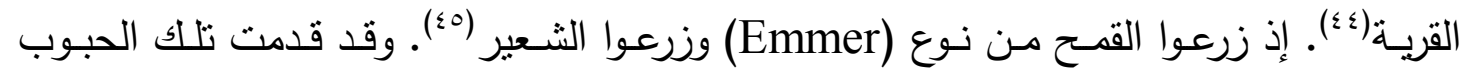
معلومات هامة عن الموقع بوجه خاص والمنطقة بوجه عام واعطت صورة واضحة عن الحياة والنشاطات الاقتصادية والحياتية فيها والتي دلت على اعتماد السكان فيها على الحبوب كغذاء رئيس لهم وتطورهم المعرفي بالزراعة وانواع المحاصيل من ذلك العثور على مخلفات وبقايا

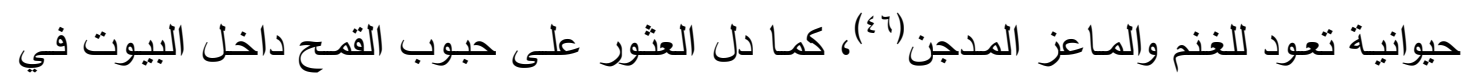
القرية على الاعتماد والتأمين الغذائي التام لسكانها كمدر اسـاس في غذائهم كما أثرنا آنفاً. وكذلك قيامهم بخزن تلك الحبوب داخل تلك البيوت في اشارة للتحوطات وحرص السكان على توفير وتأمين الحبوب الغذائيسة تحسبا" للظروف الطارئة التي قد تحدث للزراعة ولاسيما" في مواسم قلة سقوط الأمطار وتأثيراتها على الأنتاج الزراعي وتوفير المحاصبل الزراعيـة وبشكل 
ومن المواقع الآثرية للقرى الممثلة للعصر الحجري الحديث في مصر السفلى موقع قرية وجد في منخفض الفيوم الممتد على طول حافة البحيرة الجافة المعروفة باسم (الفيوم) التي كانت تملؤها المياه فيما مضىى(§) إذ كانت المياه فيها في الألف الخامس قبل الميلاد اعلى مما هي عليه الآن بمقدار ( • ^) قدماً(^§). وتعد حضارة الفيوم التي يعود إليها موقع القرية من أقدم وأبرز حضـارات مصر والثـرق الأدنى القديم، إذ عثر فيها بقايـا خلفها سكان الموقع ومنها مخلفات

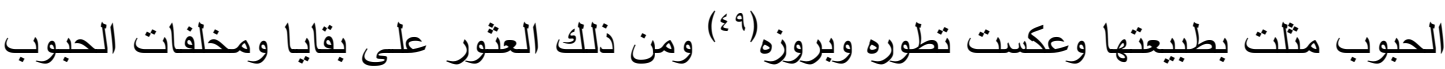
متمثلة بـالقمح من نوع (Emmer) والثـعير الذي عثر على بقايـاه في صـوامع تحت الارض مبطنة بالحصير(·). مما يشير الى الغرض ذاته الذي سبقت الاشارة اليه في قريـة (دير طاسـة) وتنابه الظروف البيئية والمناخية نفسها في كلتا القريتين • ومن المواقع الأثربـة التي أثبتت التتقيبات الأثربـة فيه موقع قريـة (مرمدة) أو (مرمدة سـلامة)(اه) وبمثنل موقع القربـة مرحلـة متأخرة من العصر الحجري الحديث ويقع على الحافة الغربية من الدلتا على بعد كيلومتربن غربي فرع الرشيد من نهر النيل(ro). وتبلغ مساحة الموقع

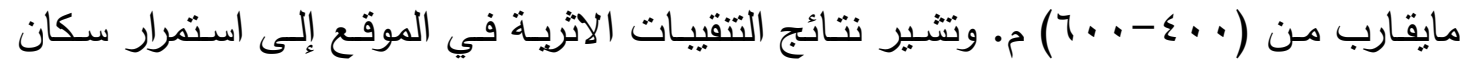
الموقع في ممارسـات العهدين السـابقين في قريتي ( طاسـة والفيوم ) في زراعـة القهـح والثعير

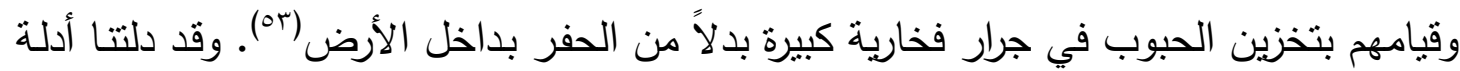
تلك الحبوب إلى استمرار التقاليد السابقة والمتواصلة لسكانها بأمور الزراعة من سكان المواقع السـابقة لموقع قريتهم المشـار إليها آنفاً، كمـا دل تخزين الحبوب في جرار فخاريـة كبيرة إلى احتمال تعرض القرية والمنطقة إلى الجفاف نتيجة قلة التساقط المائي أو تذبذب المصادر المائية الأرضية وعدم استقرار الظروف المناخية والبيئية اللازمـة للعمليات الزراعية والذي ختم عليهر خزن نلك الحبوب في جرار فخارية كبيرة. צ - ايران:

مثلت المواقع الآثارية في ايران والتي تم العثور فيها على بقايا ومخلفات الحبوب احد اهم المواقع في منطقة الثـرق الادنى القديم ، إذ لعبت العوامل البيئيـة والمناخيـة والتضـاريسية

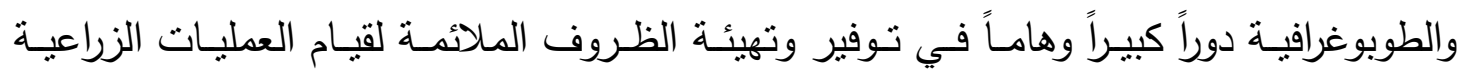
الخاصـة بزراعـة الحبـوب، أذ أعطـت بقايـا الحبوب المتفحمـة في تلك المواقع معلومـات هامـة وقدمت صورة واضحة ومدلولات جلية مكنت الباحثين من أستتباط المعلومات وتحليلها ودراستها عن تلك المواقع • وقد انعكست تلك الطوبوغرافية والتضـاريس والانماط المناخية المرتبطة بها على ظروف زراعة الحبوب فيها والتي قدمت معلومات هامـة وبالغـة وعكست طبيعـة المنطقة وجوانبها وظروفها التي أثنـرنا إليها آنفاً عـلاوة على الجوانب والنشـاطات الاقتصـادية والحياتيـة 
للمواقع الآثارية التي تعود إليها والمنطقة بوجه عام. ومن بين أهم وأبرز المواقع الأثرية التي تم

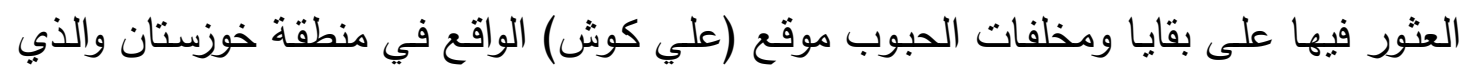

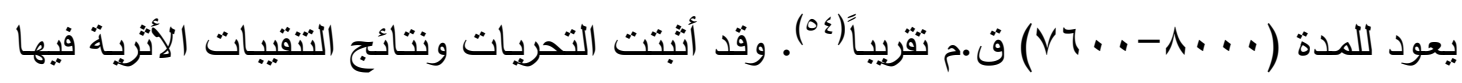

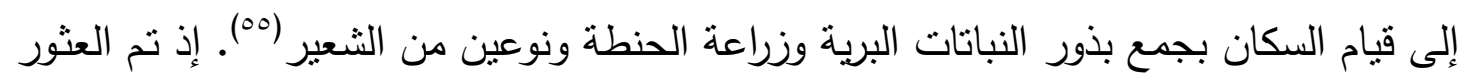

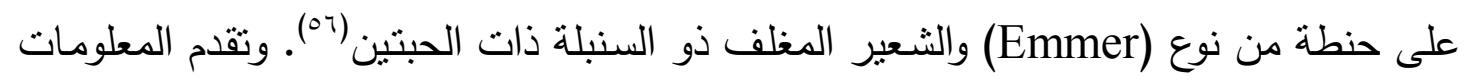
المستتبطة إلى جانب المخلفات الحيوانية في الموقع إلى توسع النشاطات الاقتصادية وتتوعها

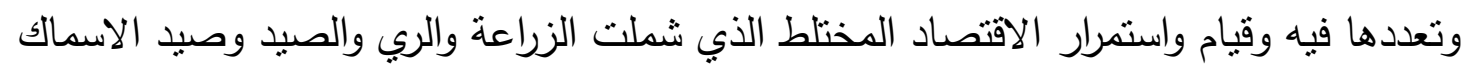

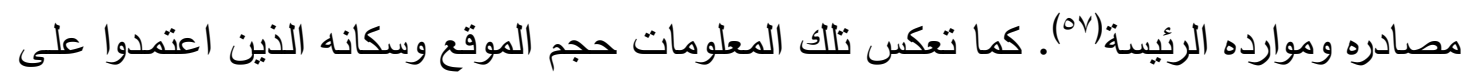

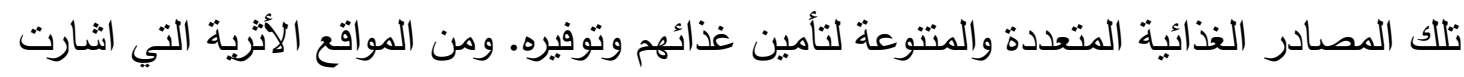

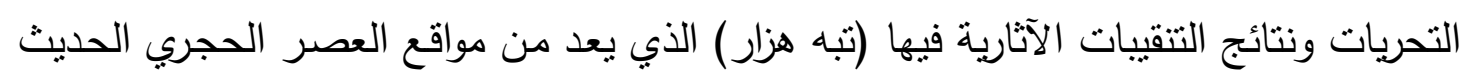

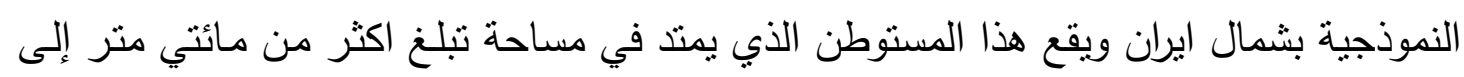

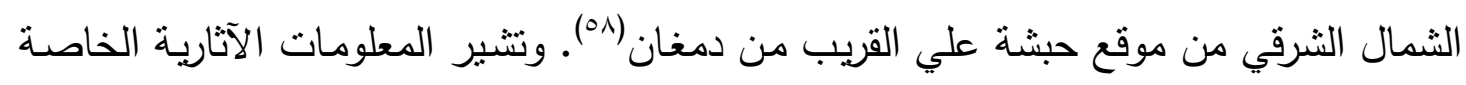

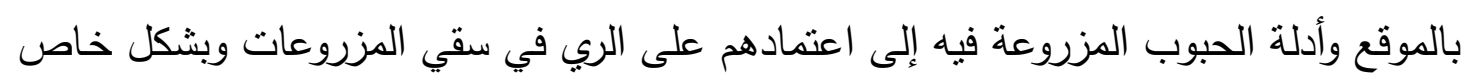
الحبوب. وتم العثور على الآلات الخاصة بسحق الحبوب وطحنها منذ المرحلة الأولى والمبكرة فيه (109.

ومن خـلال طريقة زراعـة الحبوب في الموقع والمعلومـات الخاصـة بذللك فإنها تعطي صورة عن الظروف البيئية والمناخية في الموقع والمنطقة والتي تبين عدم كفاية مسنوى التساقط

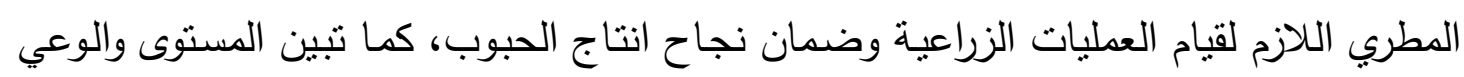

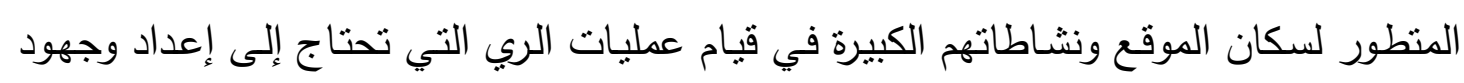

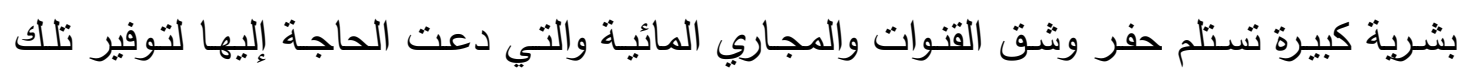

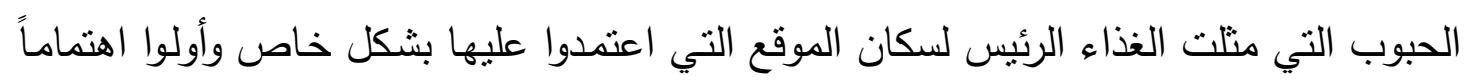

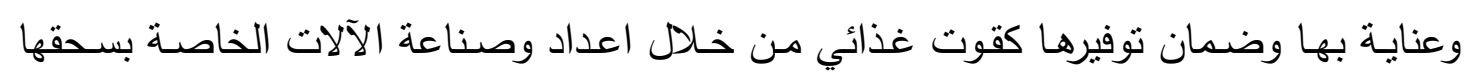

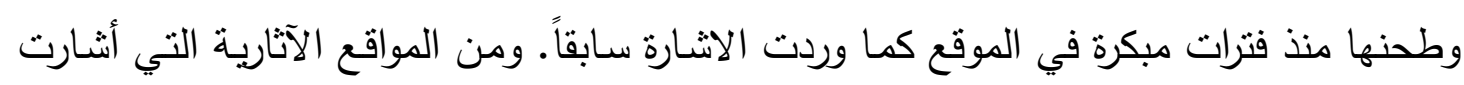

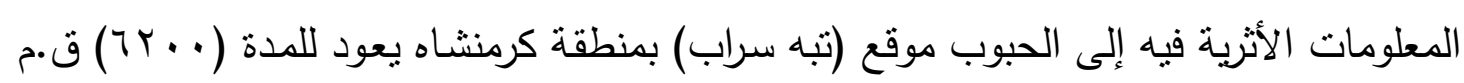

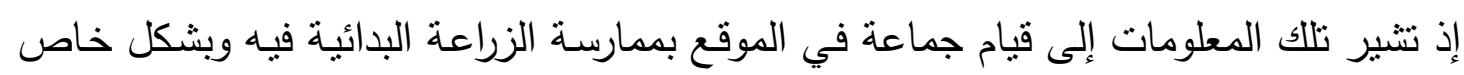
الحنطة إلى جانب مخلفات حيوانية وعلى الأخص الخنزير (.7).

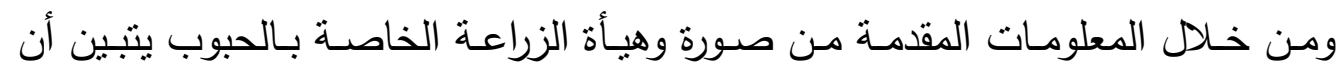

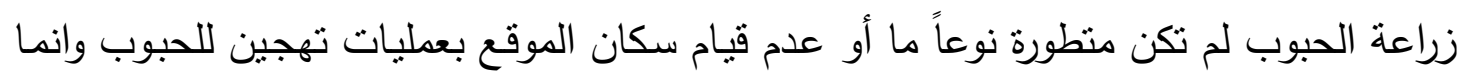

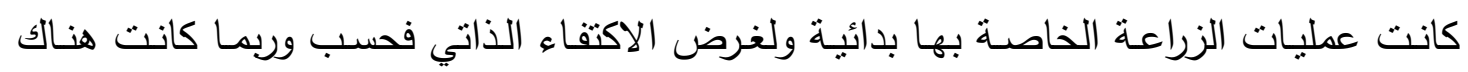




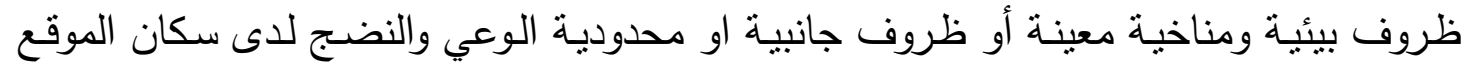
شكل السبب الأساس في ممارستهم الزراعة البدائية أو ربما لبدائية الموقع. ه - الأناضول:

شكلت المواقع الآثاريـة في بـلاد الاناضـول التي تم العثور فيهـا على مخلفات وبقايـا الحبوب اهمية بالغة ومتميزة لا تقل اهمية عن ايران المشابهة لها من الناحية البيئية والتضاريس والطوبوغرافيـة وحتى الظروف المناخية، إذ تمتاز بالتعدد والتتوع والتتاقض ايضـاً من الناحيتين الجغرافية والمناخية وبالتالي بالمنتجات الزراعية(آ). وقد شكل موقع قرية ( جاتال هويوك ) ابرز واهم المواقع التي شكلت اهمية كبيرة وبالغة في الاناضول بوجه خاص ومنطقة الثرق الادنى بوجه عام من حيث تطوره الحضاري وتطور الزراعة فيه وبشكل اساس الحبوب. يقع موقع القرية الزراعيـة في سـل قونيا إلى الثـمال من قريـة جمرة بنحو (1 (1) كم بمسـاحة من الارض تبلغن

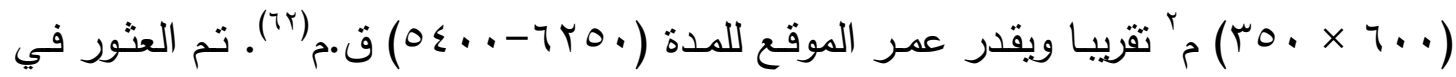
الموقع على مخلفات وبقايـا الحبوب تمنلت بنوعي الحنطة (Emmer) و (Einkorn) وحنطـة الخبز والثـعير وكانـت نلاك الأنـواع نتوفر بكثرة(rآ). وتقدم أدلـة زراعـة الحبـوب في الموقع معلومـات قيمـة ومهمـة عنـه وعن المنطقة بوجـه عـام وفي مقدمتها اعتمـاد سكان الموقع على الزراعة وبشكل رئيس الزراعة الديمية التي تعتمد عليه بشكل اسـاس بعض المحاصيل لتي لا تتمو عن طريق الري الاصطناعي وبشكل خاص البقوليات التي تم العثور على مخلفاتها وبقاياها في الموقع (ء). كذلك أفادت تللك الحبوب وقدمت معلومـات تتوافق مـع ماهيـة الموقع ومـا تم العثور عليه حجم النشـاطات الاقتصـادية والحياتيـة فيـه وكثافة سكانه المناسبة قياسـا لمسـاحته ووجود عمليات الارواء الاصطناعي التي قامت عليها الزراعة الديمية فيـه، كذللك تتوع وتعدد مصادر الغذاء والمحاصيل في الموقع نتيجة ازدياد سكانه التي كانت في تزايد مستمر استمر

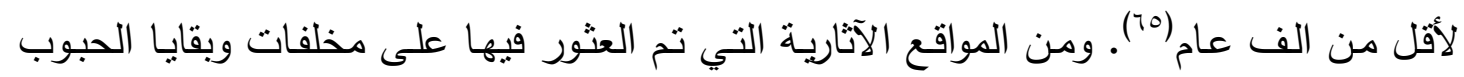

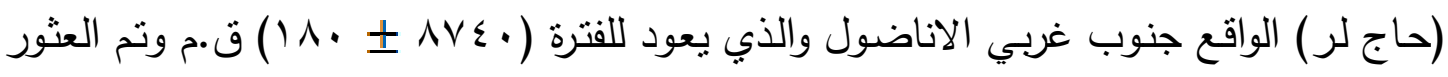
فيهه على نوع الحنطة المهجنـة من نوع (Emmer) ونوع الحنطـة البريـة (Einkorn) والثعير العادي والمغلف إلى جانب العدس وانواع عديدة اخرى(ب7). وتشير مخلفات تلك الحبوب إلى ونى معلومـات هامـة عن الموقع بوجـه خـاص والمنطقة بوجـه عـام عن الظروف البيئيـة والمناخيـة وظروف الزراعة والتي بينت توافر تلك الظروف وتكيفها للزراعة وبشكل رئيس الحبوب التي هي نجحـ زراعتهـا وتهجينهـا في الموقع كمـا أثتبتت طوبوغرافيـة وتضـاريس المنطقـة والظـروف المناخية المرتبطة بها تمتعها بمستوى مطري ملائم لقيام العمليات الزراعية بحكم وقوع الموقع الذي مثّل تناً يقع في وادي جبلي من سلسلة جبال طوروس. كما يتبين وجود نمو سكاني منزايد 
في الموقع اعتمد على تلك الحبوب التي قدمت معلومات مهمة عنه اذ تضمن سبع (V) طبقات بنائية نشكلت من غرف صغيرة ذات مخطط مسنطيل(T).

\section{الخاتمهة:}

كانت الدراسـة محاولة لإلقاء الضـوء على اهميبة الحبوب ودورها بوصفها من مصسادر المعلومات الهامـة في الكثف الآثاري لمواقع عصور قبل التاريخ والتي تعد أحد أهم عناصرها الرئيسة إلى جانب المصادر الأخرى التي متّلت مرتكزاً أساساً للمعلومات في تلك الفترة التي لا

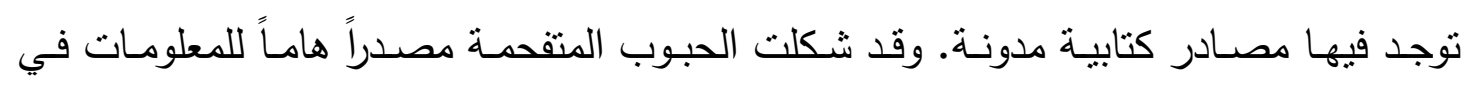
المواقع الأثريـة التي تم العثور فيها على بقاياهـا ومخلفاتها المختلفة والتي كانت بهيأة متفحمـة نتيجة مرور آلاف السنين الموغلـة في القدم عليها وتعرضـها للتفحم الذي اصسابها نتيجـة ذلك

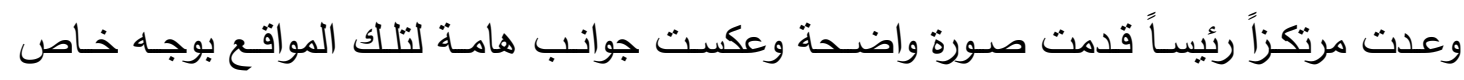
والمناطق العائدة إليها بوجه عام. كما عكست جوانب آثارية وحياتية منكاملة للمواقع الآثارية التي تم العثور على بقاياها ومخلفاتها والتي أفادت الكثف الآثاري ومجالاته عن طريق ربط تلك الجوانب وتحليلها واستتباط المعلومات الخاصـة بكل موقع الذي مثل خصوصية له. كما قدمت معلومات عن جوانب بيئية ومناطقية طوبوغرافية ونشاطات حياتية كبيرة وواضحة القت الضوء على عمليات الكثف الآثاري للمواقع التي تم العثور فيها على بقاياها ومخلفاتها والتي تعود إلى فترة عصور قبل التاريخ، إذ شكلت المعلومات التي قدمتها مـع ظروف زراعتها صورة واضحة وجليـة رســت الخطـوط العربضـة لتلـك الجوانـب التي اسـهمت في تقربـب الصـورة للبـاحثين المتخصصـين سـواءً كانوا في المجـالين الآثاري أم الزراعي الخـاص بعلم النبـات. كمـا مكنـت

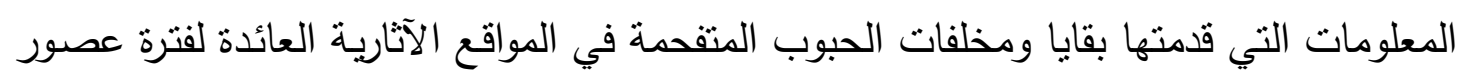
قبل التاريخ البـاحثين والمختصين من تشكيل مـادتهم الرئيسـة في دراسـاتهم البحثيـة والتطبيقيـة الحالية والمستقبلية التي بنوا عليها عمهم البحثي والتطبيقي وفق تلك المعطيات والمعلومات.

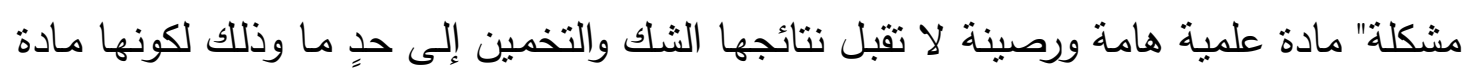
موجودة في اغلب عصور قبل التاربخ في العالم كونها مـادة غذائية أساسية للسكان في تلك الك الفترة ولا زالت ظروف زراعتها واضحة ومعروفة وعامـة لدى اغلب السكان، كما أن الظروف البيئية والمناخية ومصادر المياه التي استوجيتها عمليات زراعتها معروفة وواضحة والتي مثلت بدورها تلك الحبوب انعكاسـاً كبيراً لتلك الظروف والسكان المستهلكين لها وعكست أوضساعهم وجوانب حياتهم المتعلقة بحجم استهلاكم ونموهم ومدى وعيهم الذهني والمعرفي في التعرف على تللك الحبوب وأصنافها وخصائصها وقد مثّل ذلك قاعدة رصينة في الفترات اللاحقة لفترة عصور قبل التاريخ ترسخت وأرست النتائج والحقائق العلمية للبحث والكثف الآثاري. 
(1) كول، سونيا، ثورة العصر الحجري الحديث، ترجمة: تقي الدباغ-ناديـة سعدي الدبوني، بغداد، 9 (199،

(Y) الجنابي، محسن علي احمد-علي، يونس عبد القادر، المدخل إلى انتاج المحاصيل الحقلية، موصل، .9-V-0 ص ص (1997

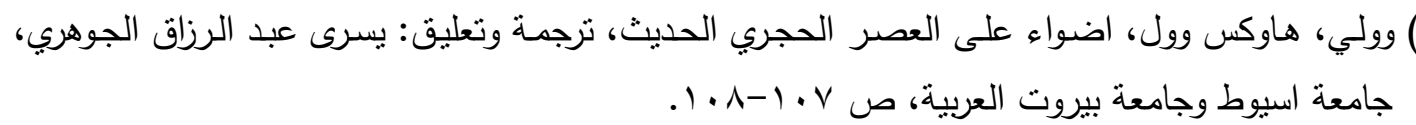

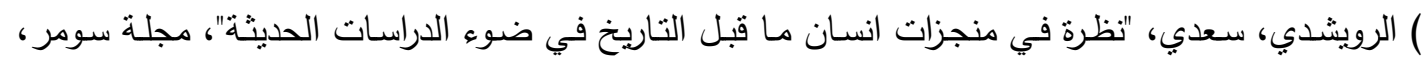

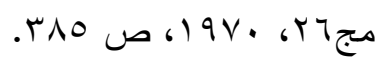

(0) حازم، حسين يوسف، "نشوء وتطور المفاهيم الاجتماعية خلال عصور مـا قبل التاريخ في العراق"، مجلة

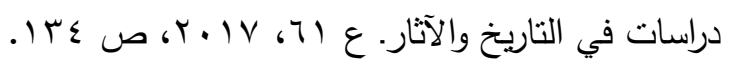

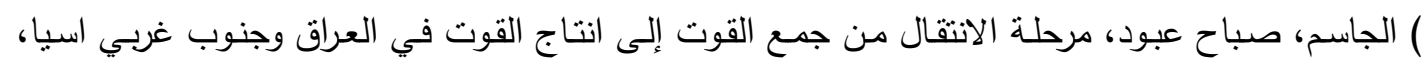

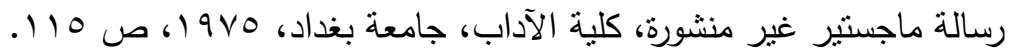

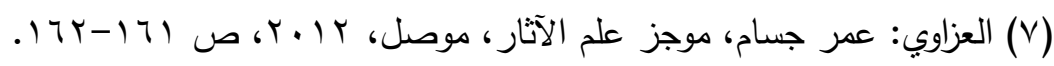

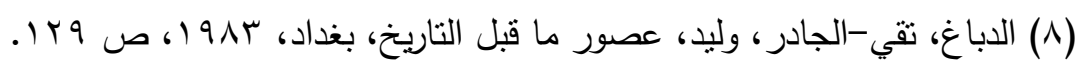

(9) الثيخ، عادل عبد الله، بدء الزراعة وأولى القرى في العراق، رسالة ماجستير غير منشورة، كلية الآداب،

جامعة بغداد، 1910 19، ص صل

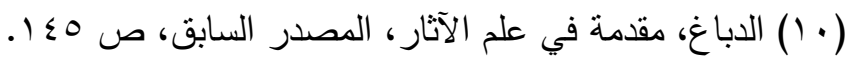

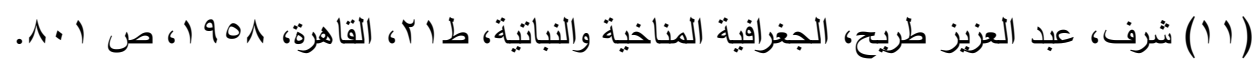

(Y ( ا ( الخاتوني، عبد العزيز الياس سلطان، أثر البيئة الطبيعية في تاريخ وحضارة بلاد الرافدين، اطروحة دكتوراه

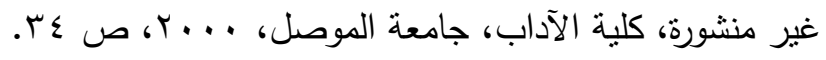

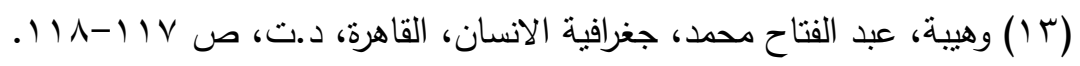

(14) Mortensen, P., "Additional Remarks on the Chronology of Early Village Farming Communities in the Zagros Area", in: Sumer, Vol. 20, 1964, pp: 22-36.

$$
\begin{aligned}
& \text { (10) رايث، المصدر السابق، ص ع ؟ ا. }
\end{aligned}
$$

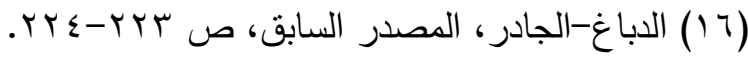

(17) Cates, C., Ancient cities, London, 2003, p. 14.

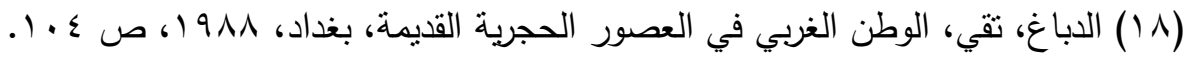

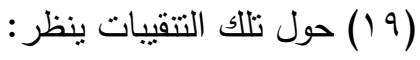

Kirkbride, D. "Umm Dagaghiyah, A Trade out Past", In: Iraq, Vol. 36, 1974, p. 29

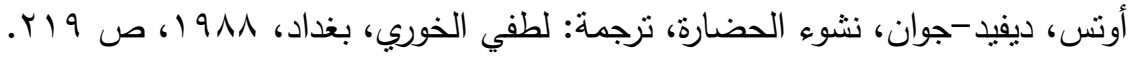

(20) Srar, C., G., A History of the Ancient World, Oxford, 1963, p. 21.

(21) Mellaart, J., Earlist Civilization of the Near East, London, 1965, p. 13.

(22) Feinman, G. M.-Price, T. Donglas, Images of the Past, California, 2001, p. 198. 
(24) BraidWood, R., Howe, B., Prehistoric Investigations in Iraqi Kurdistan, Chicago, 1960. P. 26.

(25) Helback, H., The Poleothnobotany Of The Near East And Europe, In : Prehistoric Investigations In Iraqi Kurdistan, Chicago , 1960 , P. 100 .

وينظر : الدباغ، الوطن العربي في العصور الحجرية، الدصدر السابق، ص

(26) Munchjev, R. Mi.-Merpert, N.Y.-Bader, N. O., "Archaeological Studies in the Sinjar Valley, 1980", In: Sumer, Vol. 43, , p. 45.

(27) Kirkbride, D., "Umm Dabaghiyah 1971: Apreliminary report", in: Iraq, Vol. 34, 1972 , p.5.

(28) Kirkbride, D., "Um Dabaghiyah, A Trade out past", op. cit, p. 92.

(29) El, Wailly, F. Abu Al-Soof, B. "The Excavations at Tell Es-Sawwan First preliminary Report 1964", In: Sumer, Vol. 21, 1965, p. 17.

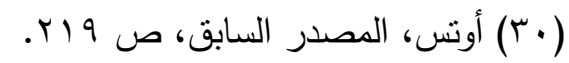

(31) Moore, A. M. T., "The Prehistoric of Syria", In: J.B.S.O.R, No. 270, 1988, p. 4.

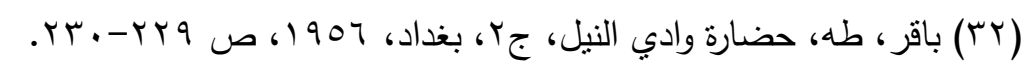

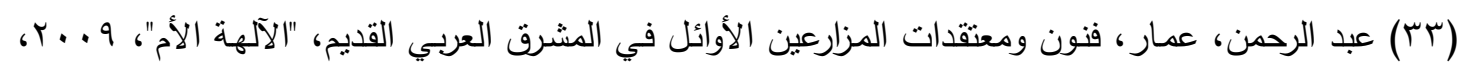

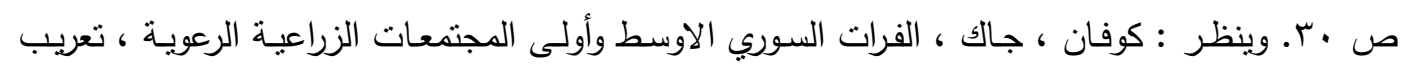

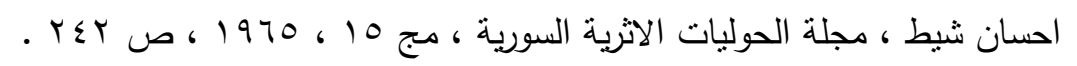

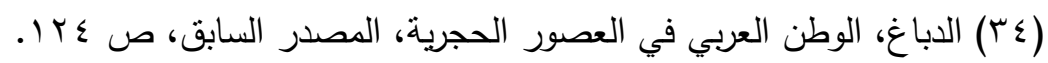

( )

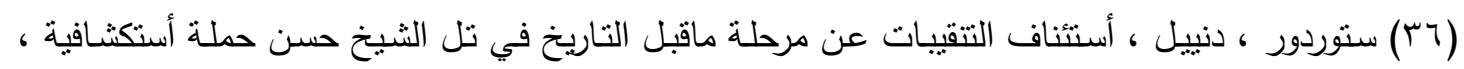

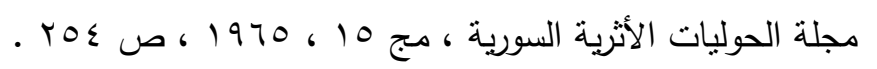

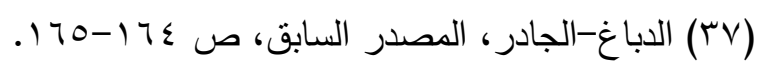

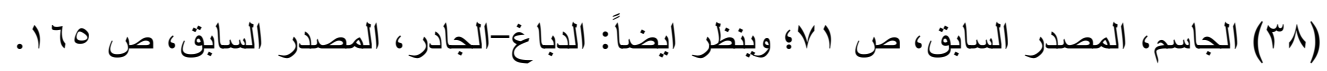

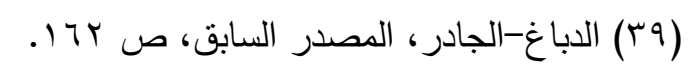

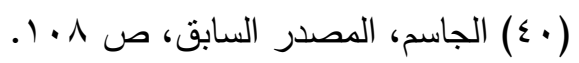

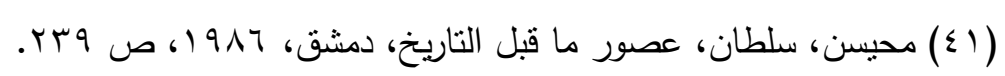

(42) Kuhrt,I,AA,,The Ancient Near East,Vol.I,London,2002,P.6.

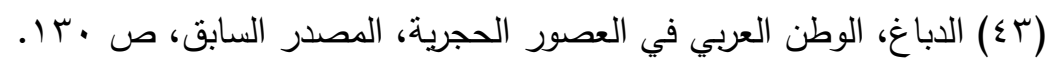

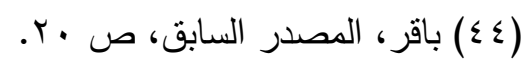

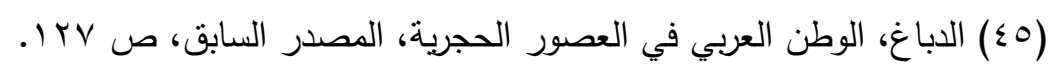

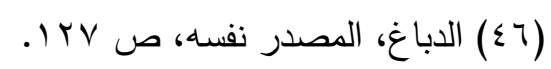

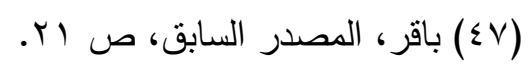

$$
\begin{aligned}
& \text { ( ) }
\end{aligned}
$$

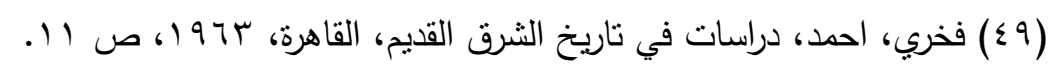

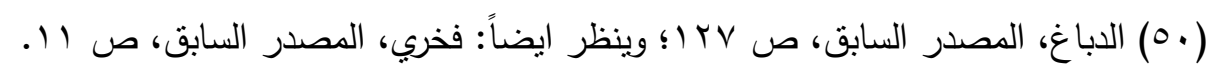

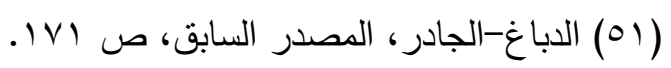


أ.م.د. حسين يوسف حازم

اهمية الحبوب المتفحمة في مواقع الحفريات الآثرية

في عصور ما قبل التاريخ - دراسة تحليلية

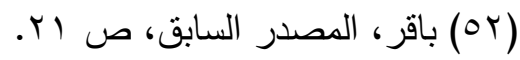

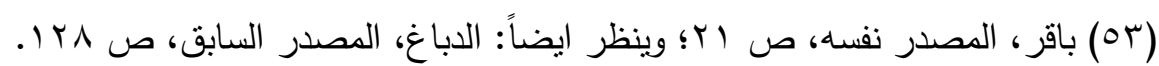

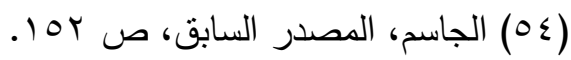

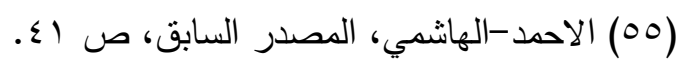

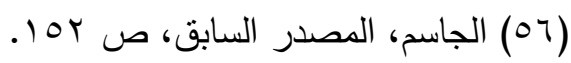

(OV) الجاسم، المصدر نفسه، ص (OV )

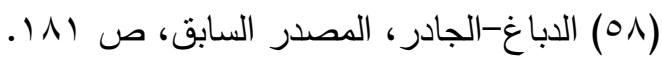

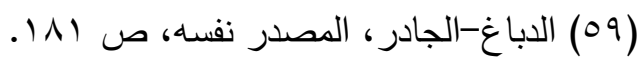

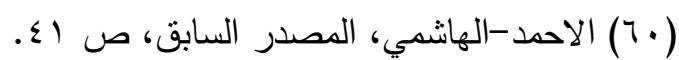

(61) Mellart, James , Earlist Civilazations Of The Near East, London , 1965 , p.13 .

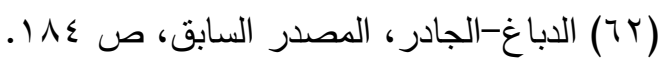

(63) Ozdogan , M - Basgelen, N., Neolithic In Turkey, Istanbul , 1999 , P. 158.

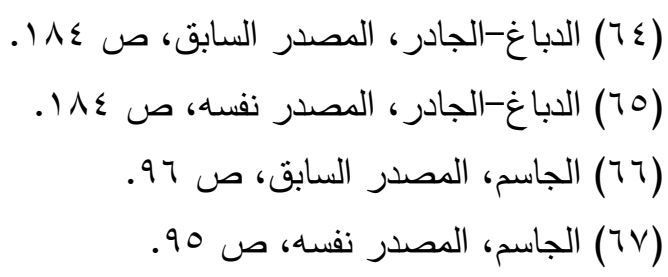




Contents

\begin{tabular}{|c|c|c|}
\hline$\overline{\text { Page }}$ & Research Name & $\overline{\text { Subject }}$ \\
\hline 1 & Prof. Khalid Salim Ismael & Preface \\
\hline $3-19$ & $\begin{array}{l}\text { Oday Abdulwahhab Al.Noamy } \\
\text { Prof. Khalid Salim Ismael }\end{array}$ & $\begin{array}{l}\text { From Epics of Kings in the Second and } \\
\text { First Millennium B.C. - An Analytical } \\
\text { Study }\end{array}$ \\
\hline $21-44$ & Prof. Dr. Farouk Ismail & The Ransom in Akkadian Texts \\
\hline $45-70$ & $\begin{array}{c}\text { Reem Mohammad Salih } \\
\text { Prof. Dr. Safwan Sami Saeed }\end{array}$ & $\begin{array}{c}\text { Assyrian's Concerns of Fear and Anxiety } \\
\text { Regarding Demons and Evil Spirits }\end{array}$ \\
\hline 71-91 & $\begin{array}{c}\text { Sondos Ali Hammadi } \\
\text { Prof. Dr. Yasser Al-Mashhadani }\end{array}$ & Sivas City before the Seljuk Rule \\
\hline $93-114$ & $\begin{array}{l}\text { Assist. Prof. Dr. Mohammed Kamil Rokan } \\
\text { Dr. Jumaa Heraz Al-Talbe }\end{array}$ & $\begin{array}{c}\text { Russian Excavations in Sinjar Region, } \\
\text { Northern Iraq }\end{array}$ \\
\hline 115-137 & $\begin{array}{c}\text { Mustafa Ahmed Ali Al-Samarrai } \\
\text { Assist. Prof. Dr. Yasmine Abdul Karim } \\
\text { Mohammed Ali }\end{array}$ & $\begin{array}{c}\text { Residential Houses from the Moncorn } \\
\text { Assyrian Period (911-612) BC. M- } \\
\text { Elected Sites from the Makhul Dam } \\
\text { Project Area }\end{array}$ \\
\hline 139-164 & $\begin{array}{c}\text { Falih Ghdwi Noman Al-Shammary } \\
\text { Assist. Prof. Dr. Haider Farhan Hussein } \\
\text { Al-Subaihawi }\end{array}$ & Heritage Mosques in Sinjar City \\
\hline $165-185$ & Assist Prof. Dr.Hussein .Y.Hazim & $\begin{array}{l}\text { Carbonated Grains and it's Role in } \\
\text { Archaeological Detection during } \\
\text { Prehistory - An Analytical Study }\end{array}$ \\
\hline $187-211$ & $\begin{array}{l}\text { Ashraf Aziz Abdul - Karim Al_Halay bik } \\
\text { Dr. Shakeeb Rashid Bashir Al- Fattah }\end{array}$ & $\begin{array}{c}\text { The Efforts of Scientific Families in } \\
\text { Building Schools and Teaching (Ibn Al- } \\
\text { Jawzi Family as a Model) }\end{array}$ \\
\hline 213-233 & $\begin{array}{l}\text { Asst. prof. Dr. Wasnaa Hasoun Younis } \\
\text { al-Aghaa }\end{array}$ & $\begin{array}{l}\text { Motives behind the Mummification of } \\
\text { Animals by the Ancient Egyptians }\end{array}$ \\
\hline $235-261$ & Dr. Aram J. Hassan Hamawand & $\begin{array}{l}\text { The Brick Completion Receipts from the } \\
\text { City of Pekasi, "Till Abu-Antik" } \\
\text { "An Analytical Study of Unpublished } \\
\text { Cuneiform Texts" }\end{array}$ \\
\hline 263-279 & $\begin{array}{l}\text { Dr. Mohanad Khalaf Jamen Al shamari } \\
\text { Hanan Abdul-Hamzah Beuawe }\end{array}$ & $\begin{array}{l}\text { Unpublished Economic Texts from Ur III } \\
\text { Dynasty }\end{array}$ \\
\hline $281-302$ & $\begin{array}{c}\text { Muthanna Saadoun Dhafer Al-Hindawi } \\
\text { Dr. Mahmoud Ibrahim Hussien } \\
\text { Dr. Dalia Mohamed El-Sayed } \\
\end{array}$ & $\begin{array}{l}\text { Demons and Evil Spirits in Ancient Iraq } \\
\text { in Light of Cuneiform Texts }\end{array}$ \\
\hline
\end{tabular}


12- The original research papers submitted to the magazine are not returned to their owners, whether published or not.

13- Tables and figures are numbered in a row according to their appearance in the research, provided with titles, submitted with separate papers, blueprints are submitted in black ink and images to be in high resolution.

14- The marginal numbers are written in parentheses and are presented in series at the end of the research.

15- The full source name is indicated in the margin, with the abbreviated source in parentheses at the end of the margin.

16- The researcher is responsible for correcting the linguistic and typographical errors in his research.

17- The magazine operates according to self-funding. Therefore, the researcher bears the publication fees of $(100,000)$ one hundred thousand Iraqi dinars.

18- Each researcher shall be provided with one copy of his research. As for the full copy of the journal, it is requested from the magazine's secretariat and a price is determined by the Editorial Board.

19- The papers should be sent to the journal e-mail:

uom.atharalrafedain@gmail.com 


\section{Publishing rules in Athar Al-Rafedain Journal (AARJ):}

1- The journal accepts scientific research that falls in specializations:

- Ancient Archaeology and Islamic Archaeology .

- Ancient languages with their dialects and comparative studies.

- Cuneiform Inscriptions and ancient lines.

- Historical and cultural studies

- Archaeological geology.

- Archaeological survey techniques.

- Anthropological studies.

- Conservation and restoration.

2- Research papers shall be submitted to the magazine in both Arabic and English.

3- The research shall be printed on (A4) paper, word-2010 system, with double spaces between lines, Simplified Arabic font for Arabic language, Times New Roman for English language, delivered on $\mathrm{CD}$, and in two paper based copies.

4- The title of the research should be printed in the middle of the page, followed by the name of the researcher, his academic degree, his full work address, and e-mail.

5- The research should contain an abstract in Arabic and English languages, it shouldn't exceed (100) words.

6- The abstract of the research in English contains the title of the research, the name of the researcher, his academic degree, his full workplace, and his e-mail.

7- The research must include keywords related to the title of the research and its content.

8- That the research was not previously published or was submitted to obtain a degree or is derived from the intellectual property of another researcher, and the researcher must undertake this in writing when submitting it for publication.

9- The researcher is obliged to follow the correct scientific foundations in his research.

10- The researcher is obligated to amend his research terms to suit the experts 'suggestions and the method of publishing in the journal.

11- The number of research pages does not exceed (25) pages, and in case of exceeding the required number, the researcher shall pay an additional amount for each additional page. 


\author{
Arabic Language Expert \\ Dr. Maan Yahya Mohammed \\ Dep. Of Arabic Language /College of Arts / University of Mosul
}

\author{
English Language Expert \\ Assist. Lect. Ammar Ahmed Mahmood \\ Dep. Of Translation Language / College of Arts / University of Mosul
}

Design Cover

Dr. Amer Al-Jumaili 


\title{
$\underline{\text { Editorial Board }}$
}

\author{
Prof. Khalid Salim Ismael \\ Editor-in-Chief
}

\section{Assist Prof. Hassanein Haydar Abdlwahed \\ Managing Editor}

\section{Members}

Prof. Elizabeth Stone

Prof. Adeileid Otto

Prof. Walther Sallaberger

Prof. Nicolo Marchetti

Prof. Hudeeb Hayawi Abdulkareem

Prof. Jawad Matar Almosawi

Prof. Rafah Jasim Hammadi

Prof. Abel Hashim Ali

Assist Prof. Yasamin Abdulkareem Mohammed Ali

Assist Prof. Vyan Muafak Rasheed

Assist Prof. Hani Abdulghani Abdullah 



\section{Journal}

\section{Athar Al-Rafedain}

Accredited Scientific Journal

It Search's in Archaeology of Iraq and Ancient Near East

Published by College of Archaeology - University of Mosul

E-Mail: uom.atharalrafedain@gmail.com

Vol.6 / No.1

Rejab. 1442 A.H. / Feb. 2021 A.D. 

University of Mosuil College of Archaedogy

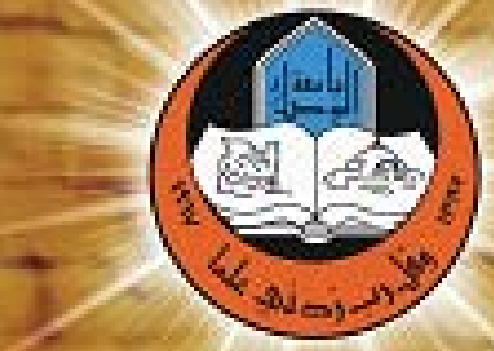

Ministry of Higher

Education and Sclentific

Research

ISSN $2304-103 X$

【RPG|

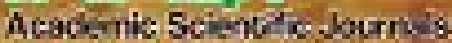

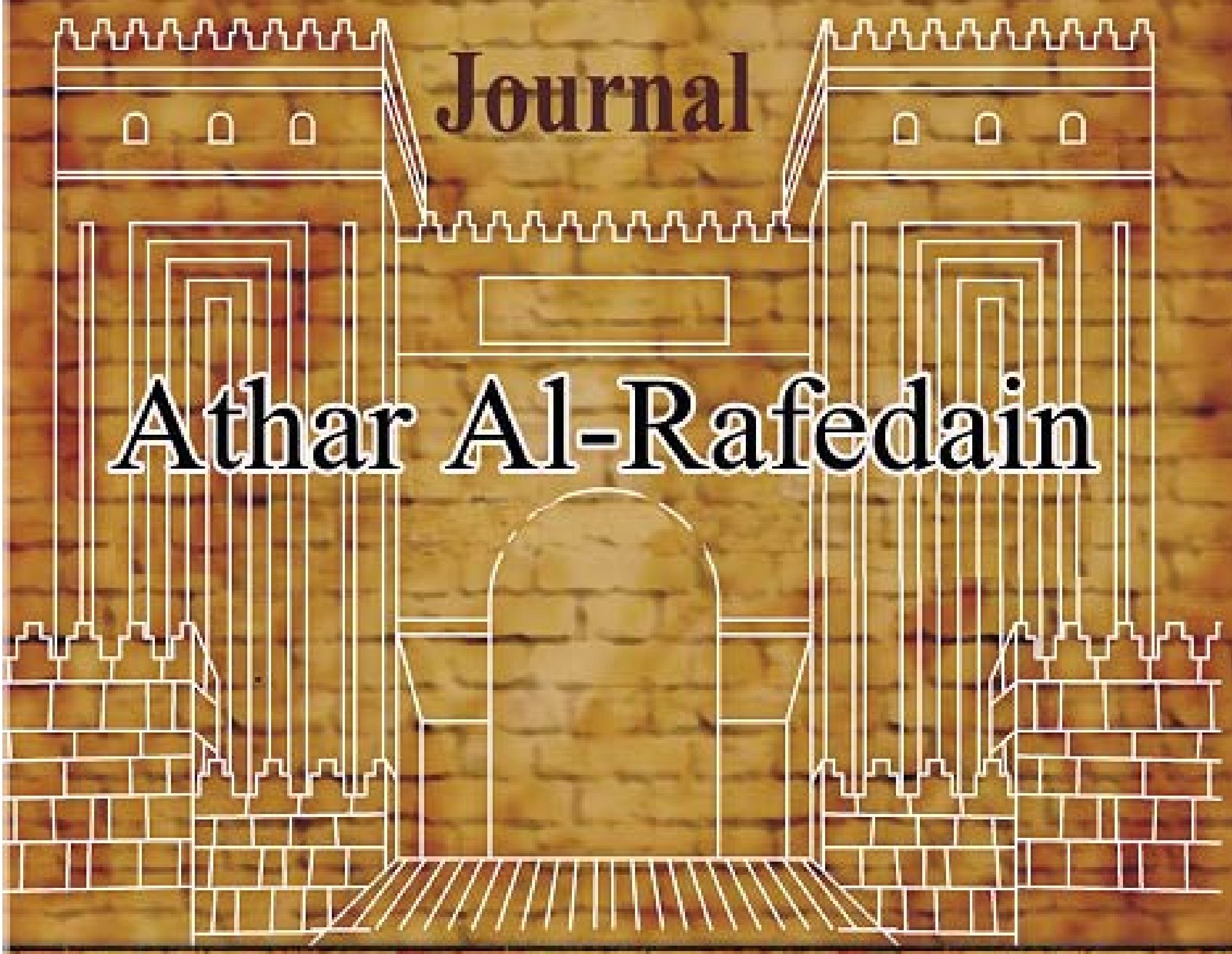

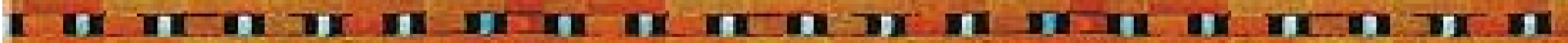

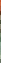

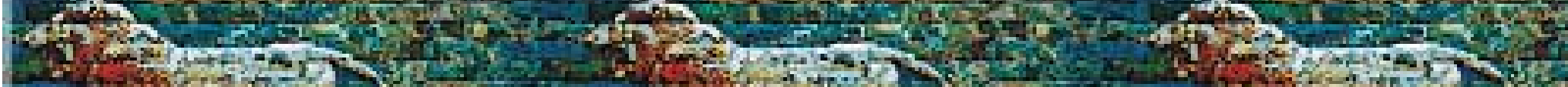

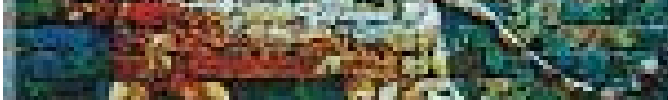
W.

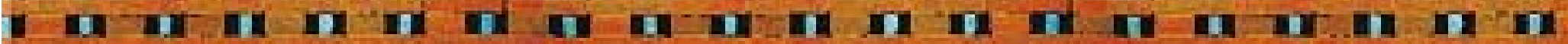

Accredited Scientific Journal it Search's in Archaeology of Iraq and Ancient Near East

Published College of Archaeology - University of Mosul / Vol.6/ No.1 / 1442 A.H. / 2021 A.D. 